\title{
The evolution of sub-monsoon systems in the Afro-Asian monsoon region during the Holocene - comparison of different transient climate model simulations
}

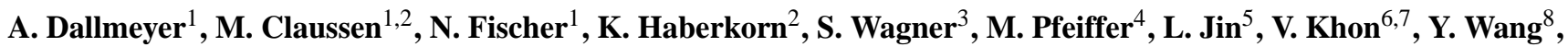 \\ and U. Herzschuh ${ }^{8,9}$ \\ ${ }^{1}$ Max Planck Institute for Meteorology, Bundesstrasse 53, 20146 Hamburg, Germany \\ ${ }^{2}$ Meteorological Institute, Centrum für Erdsystemforschung und Nachhaltigkeit (CEN), Universität Hamburg, \\ Bundesstrasse 55, 20146 Hamburg, Germany \\ ${ }^{3}$ Helmholtz Center Geesthacht, Institute for Coastal Research, 21502 Geesthacht, Germany \\ ${ }^{4}$ Alfred Wegener Institute for Polar and Marine Research, 27568 Bremerhaven, Germany \\ ${ }^{5}$ Key Laboratory of Western China's Environmental Systems, Lanzhou University, Research School of Arid Environment and \\ Climate Change, Lanzhou 730000, China \\ ${ }^{6}$ Institute of Geosciences, Christian-Albrechts Universität zu Kiel, Ludewig-Meyn-Str. 10-14, 24118 Kiel, Germany \\ ${ }^{7}$ A. M. Obukhov Institute of Atmospheric Physics RAS, Pyzhevsky 3, 117019 Moscow, Russia \\ ${ }^{8}$ Alfred Wegener Institute for Polar and Marine Research, Telegrafenberg A43, 14473 Potsdam, Germany \\ ${ }^{9}$ Institute of Earth and Environmental Science, University of Potsdam, Karl-Liebknecht-Strasse 24-25, \\ 14476 Potsdam, Germany
}

Correspondence to: A. Dallmeyer (anne.dallmeyer@mpimet.mpg.de)

Received: 29 March 2014 - Published in Clim. Past Discuss.: 15 May 2014

Revised: 22 January 2015 - Accepted: 26 January 2015 - Published: 19 February 2015

\begin{abstract}
The recently proposed global monsoon hypothesis interprets monsoon systems as part of one global-scale atmospheric overturning circulation, implying a connection between the regional monsoon systems and an in-phase behaviour of all northern hemispheric monsoons on annual timescales (Trenberth et al., 2000). Whether this concept can be applied to past climates and variability on longer timescales is still under debate, because the monsoon systems exhibit different regional characteristics such as different seasonality (i.e. onset, peak and withdrawal). To investigate the interconnection of different monsoon systems during the pre-industrial Holocene, five transient global climate model simulations have been analysed with respect to the rainfall trend and variability in different sub-domains of the Afro-Asian monsoon region. Our analysis suggests that on millennial timescales with varying orbital forcing, the monsoons do not behave as a tightly connected global system. According to the models, the Indian and North African monsoons are coupled, showing similar rainfall trend and moderate correlation in centennial rainfall variability in all models.
\end{abstract}

The East Asian monsoon changes independently during the Holocene. The dissimilarities in the seasonality of the monsoon sub-systems lead to a stronger response of the North African and Indian monsoon systems to the Holocene insolation forcing than of the East Asian monsoon and affect the seasonal distribution of Holocene rainfall variations. Within the Indian and North African monsoon domain, precipitation solely changes during the summer months, showing a decreasing Holocene precipitation trend. In the East Asian monsoon region, the precipitation signal is determined by an increasing precipitation trend during spring and a decreasing precipitation change during summer, partly balancing each other. A synthesis of reconstructions and the model results do not reveal an impact of the different seasonality on the timing of the Holocene rainfall optimum in the different submonsoon systems. Rather they indicate locally inhomogeneous rainfall changes and show that single palaeo-records should not be used to characterise the rainfall change and monsoon evolution for entire monsoon sub-systems. 


\section{Introduction}

Monsoon systems are coupled atmosphere-ocean-land phenomena that are primarily driven by seasonal and latitudinal differences in incoming solar radiation. The different heat capacities of oceans and continents lead to strong thermal contrasts forming large-scale atmospheric circulations that reverse seasonally and are characteristically accompanied by summer rainfall and winter dryness (Webster et al., 1998). Changes in any component of the climate system affect the monsoon circulations and result in strong temporal climate variability on all timescales (e.g. Ding, 2007; Lau et al., 2000; Wang, 2006). The most pronounced monsoon systems are the North African and Asian monsoon, incorporating the Indian and East Asian monsoon sub-systems.

Prior to the satellite era, observational data of monsoon precipitation and circulations were scarce, particularly above the oceans. By the use of remote sensing, monitoring of all monsoon systems has been enabled. The in-phase movement of the global monsoon systems partly visible in the seasonal migration of the Intertropical Convergence Zone (ITCZ) led to the development of a new monsoon concept, i.e. the global monsoon hypothesis (Trenberth et al., 2000). This concept suggests that all monsoon systems are part of one seasonal varying global-scale atmospheric overturning circulation in the tropics and subtropics forced by the annual cycle of insolation and the resultant global divergent motion. Furthermore, for instance, the African and Indian monsoon share similar decadal variability (Feudale and Kucharski, 2013). Whether the global monsoon concept can be applied to past climates and variability on longer timescales is not yet clear (Trenberth et al., 2000), although palaeomonsoon studies reveal similarities to the modern global monsoon concept regarding palaeomonsoon evolution, e.g. similar longterm monsoon intensity oscillations in different monsoonsubdomains (Cheng et al., 2012).

During the early Holocene, the main changes in surface boundary conditions compared to the present day were the remnant Laurentide ice sheet and differences in the seasonal incoming solar radiation. For instance, 9000 years ago $(9 \mathrm{k})$, the cyclic variations in the Earth's orbital configuration (mainly the precession) led to a $10 \%$ higher summer insolation on the Northern Hemisphere compared to today (Berger, 1978). In contrast, winter insolation was decreased by $10 \%$ yielding only small changes in the annual mean insolation, but an increase of the amplitude of the seasonal insolation cycle. While the insolation differences have continuously decreased throughout the Holocene, the present extent of the Northern Hemisphere ice sheet was already reached during mid-Holocene. According to the global monsoon concept (Trenberth et al., 2000) and Kutzbach's orbital monsoon hypothesis of northern hemispheric summer insolation driving the summer monsoon evolution at precessional scale (Kutzbach, 1981; Ruddiman, 2006), one would expect that all boreal summer monsoon systems react similarly to this insolation change. This would imply an intensification of the summer monsoon strength and an increased summer precipitation in the early and mid-Holocene followed by a gradual decrease of both climate variables in the course of the time towards the present day.

Indeed, many palaeoenvironmental records reveal enhanced northern hemispheric monsoon circulations and more rainfall during the early and/or mid-Holocene (e.g. Fleitmann et al., 2003; Jolly et al., 1998; Peyron et al., 2006; Prasad and Enzel, 2006; Wang et al., 2005). However, not all reconstructions show a synchronous trend within and among the different sub-monsoon regions. For the North African monsoon area, for instance, some records are indicative of an abrupt end of the humid period around $5 \mathrm{k}$ (e.g. deMenocal et al., 2000), whereas other records suggest a gradual decline in annual precipitation during the Holocene (e.g. Kropelin et al., 2008; Francus et al., 2013). The timing of maximum Holocene rainfall in the Asian monsoon region strongly depends on the location (e.g. An et al., 2000) and the affecting monsoon sub-system (Maher, 2008; Maher and $\mathrm{Hu}, 2006)$. While moisture levels in the Indian monsoon region are highest during the early Holocene, the East Asian monsoon did not reach maximum strength before the midHolocene (Herzschuh et al., 2006; Wang et al., 2010). On longer timescales, the precessional cycle is shared by most monsoon systems, but Chinese speleothems lag the insolation curve by $4 \mathrm{ka}$, northern African records by $2.6 \mathrm{ka}$ and Indian records by $8 \mathrm{ka}$ (cf. Caley et al., 2011 and references therein), showing no uniform response to the insolation forcing.

Various suggestions of possible explanations for the deviating precipitation trends exist, but so far the causal relationships are not clear. Among other reasons, the differences in rainfall trends could be attributed to previous misinterpretation of the data (Cheng et al., 2012 and references therein; Maher and Thompson, 2012) and/or differences in the characteristics of the monsoon sub-systems: at least partly, the monsoon response to the orbitally controlled insolation forcing is affected by differences in the land-sea settings (e.g. Wang et al., 2003, 2013; Wang, 2009) that probably also have an impact on the strength of the involved ocean-atmosphere feedbacks. The Indian and North African monsoon circulations are determined by a meridional and interhemispheric land-ocean contrast, while the East Asian monsoon is characterised by a zonal land-sea contrast (Wang et al., 2001). Furthermore, the impact of other large-scale circulation systems (e.g. the Westerly wind system) varies among the different monsoon sub-systems. For instance, the Indian monsoon system is less affected by mid- and high-latitude climate processes than the East Asian monsoon (Huang et al., 2012). All monsoon systems show differences in the seasonal cycle, particularly in the timing of onset, rainfall peak and withdrawal. These differences in the seasonality of the sub-monsoons may lead to differences in the response of the 
monsoon system to the Holocene change in seasonal insolation.

Thus, whether the monsoon systems evolve synchronously or asynchronously during the Holocene, i.e. if the global or regional aspect of monsoons predominates on millennial timescales, is still under debate. To investigate Holocene precipitation trends in different parts of the Afro-Asian monsoon region and to test the connectivity of the different monsoon sub-systems in this region, we analyse five transient climate simulations covering the last 6000 years, which have been performed using various coupled atmosphere-ocean(vegetation) models. We focus on the following research questions:

1. Can state-of-the-art climate models capture the reconstructed precipitation trends in the Afro-Asian monsoon region, e.g. retrieved from speleothem records?

2. Do the simulations reveal a synchronous precipitation response to the Holocene insolation forcing for all subdomains, supporting the global monsoon hypothesis on longer time-scales?

3. If differences in the precipitation trend among subdomains exist, which controlling mechanisms can be retrieved from the model results, for instance in the context of changes in the seasonal insolation cycle and differences in the seasonality of the monsoon sub-systems?

After a short description of the models, simulations and methods used in this study, we first assess the performance of the models concerning the representation of the modern precipitation distribution in the Afro-Asian monsoon domain (Sect. 3.1). The second part of the results deals with the precipitation change from mid-Holocene to present-day times including a comparison of the precipitation trends in the different models (Sects. 3.2-3.4). Based on these results, we discuss whether the transient simulations support the global monsoon hypothesis for the Holocene monsoon evolution (4.2) and analyse the effect of the differences in seasonality on the Holocene monsoon response (4.3) as this is the only hypothesis for the deviating precipitation trends we can analyse with this setup of simulations.

\section{Methods}

\subsection{Model description and experimental design}

To investigate the Holocene rainfall trend in the Afro-Asian monsoon system, we analyse five transient climate model simulations that have been performed in a wide spectrum of coupled atmosphere-ocean-(vegetation) models (cf. Table 1). In the following, the models and simulations are introduced briefly; for further details on the simulations we refer to the original manuscripts.

\subsubsection{COSMOS and COSMOSacc}

COSMOS is the model of the Community Earth System models network, initiated by the Max Planck Institute for Meteorology, Hamburg, Germany. The model consists of the general circulation model for the atmosphere ECHAM5 (Roeckner et al., 2003) coupled to the land-surface scheme JSBACH (Raddatz et al., 2007) and the ocean model MPIOM (Marsland et al., 2003). In the version used in this study, JS$\mathrm{BACH}$ included the dynamic vegetation module of Brovkin et al. (2009) representing eight different plant functional types. MPIOM was integrated with a horizontal resolution of approximately $3^{\circ}$ and 40 levels in the vertical. ECHAM5 was set up in a spectral resolution of T31L19 corresponding to a longitudinal distance of approx. $3.75^{\circ}$ on a great circle and 19 levels in the vertical.

In this setup, two transient experiments have been performed. The first (COSMOS) was conducted by Fischer and Jungclaus (2011) and started at mid-Holocene climate conditions (6000 years ago). The model was brought to a quasiequilibrium climate state prescribing mid-Holocene insolation forcing and pre-industrial atmospheric conditions (e.g. $\mathrm{CO}_{2}$ composition of $280 \mathrm{ppm}$ ). Afterwards, the orbital configuration was changed yearly until present-day conditions were reached. The chemical composition of the atmosphere stayed constant during the entire simulation. This simulation covers the last 6000 years. The data of this simulation are available as snapshots (every 50 years) in the PANGAEA database (Fischer and Jungclaus, 2012).

The second simulation (COSMOSacc) was performed by Pfeiffer et al. (2013) (Varma et al., 2012; Pfeiffer and Lohmann, 2013) in the same way as the first simulation, but using an orbital forcing accelerated by a factor of 10 . This means that the period between the mid-Holocene and the preindustrial period is represented by only 600 instead of 6000 model years. The chemical composition of the atmosphere was fixed to pre-industrial values. Similar experiments were also carried out by Lorenz and Lohmann (2004) with the ECHO-G model using the acceleration technique for investigations of the climate of the Holocene.

\subsubsection{ECHO-G}

ECHO-G (Legutke and Voss, 1999) consists of the atmospheric general circulation model ECHAM4 (Roeckner et al., 1996) and the ocean model HOPE-G (Wolff et al., 1997). A dynamic vegetation model was not included in this setup. The vegetation is set to present-day conditions throughout the entirety of the simulations. ECHAM4 had a numerical resolution of T31L19 corresponding to approx. $3.75^{\circ}$ on a great circle and 19 levels in the vertical. HOPE-G had 20 irregularly spaced vertical levels and an effective horizontal resolution of $2.8^{\circ} \times 2.8^{\circ}$ increasing to $0.5^{\circ}$ towards the Equator. In contrast to the newer COSMOS generation the ECHO-G model is flux corrected for heat and fresh water 
Table 1. Overview of all transient climate simulations considered in this study, including resolution (Res.), application of the forcing (Acc.), i.e. accelerated or not, and handling of dynamic vegetation in the model.

\begin{tabular}{|c|c|c|c|c|c|c|}
\hline Simulation & Model & Reference & Res. & Forcing & Acc. & Dyn. veg \\
\hline COSMOS & ECHAM5/JSBACH-MPIOM & Fischer and Jungclaus (2011) & T31L19 & Orbit & No & Yes \\
\hline ECHO-G & ECHAM4-HOPE-G & Wagner et al. (2007) & T31L19 & Orbit & No & No \\
\hline PLASIM & PlaSim-LSGocean-Simba & Haberkorn (2013) & $\mathrm{T} 21 \mathrm{~L} 10$ & Orbit + GHG & No & Yes \\
\hline COSMOSacc & ECHAM5/JSBACH-MPIOM & $\begin{array}{l}\text { Varma et al. (2012); } \\
\text { Pfeiffer and Lohmann (2013) }\end{array}$ & T31L19 & Orbit & Yes & Yes \\
\hline $\mathrm{KCM}$ & ECHAM5-NEMO & Jin et al. (2014) & T31L19 & Orbit & Yes & No \\
\hline
\end{tabular}

in order to avoid climate drift. The model was brought to a quasi-equilibrium climate state using a mid-Holocene $(7 \mathrm{k})$ orbital configuration (Wagner et al., 2007). Afterwards, the insolation forcing was changed after each model year. In the transient simulation used in this study, the chemical composition of the atmosphere was kept constant at pre-industrial levels. The first part of this simulation (7000BP-4500BP) is available on the CERA database (Wagner, 2007).

\subsubsection{PLASIM}

PlaSim is an atmosphere model of medium complexity (Fraedrich et al., 2005) and was used in a horizontal resolution of T21 (approx. 5.6 $\times 5.6^{\circ}$ on a Gaussian grid) and 10 levels in the vertical. In the simulation used for this study (Haberkorn, 2013), PlaSim was coupled to the ocean model LSG (Maier-Reimer et al., 1993) and the vegetation module SimBA (Kleidon, 2006). The model had been brought to quasi-equilibrium in early Holocene climate conditions (10 k orbit and atmospheric composition). Then the transient simulation was started using yearly adapted orbital forcing (Berger, 1978). Holocene variations in atmospheric $\mathrm{CO}_{2}$ concentration were additionally prescribed from Taylor Dome reconstructions (Indermuhle, 1999). For instance, atmospheric $\mathrm{CO}_{2}$ content was changed from $265-$ $269 \mathrm{ppm}$ during the mid-Holocene to the pre-industrial level $(280 \mathrm{ppm})$. The effect of increasing $\mathrm{CO}_{2}$ during the preindustrial Holocene is relatively small compared to changes in orbital forcing. Therefore, we do not expect any substantial impact of the varying $\mathrm{CO}_{2}$ concentration on the results of this study. Here, the last 6000 years of this simulation were used.

\subsubsection{KCM}

The Kiel Climate Model (KCM, Park et al., 2009) is a coupled atmosphere-ocean-sea ice general circulation model. The atmosphere is represented by ECHAM5 (Roeckner et al., 2003) that ran in the numerical resolution T31L19 corresponding to $3.75^{\circ}$ on a great circle. ECHAM5 is coupled to the ocean-sea ice model NEMO (Madec, 2006) that ran with a horizontal resolution of approx. $2^{\circ} \times 2^{\circ}$ and increased meridional resolution $\left(0.5^{\circ}\right)$ close to the Equator.
The coupled model had been brought to a quasi-equilibrium climate state with the early Holocene orbital configuration (9.5 k) before the transient simulation started using orbital forcing only (Jin et al., 2014). The forcing, i.e. change in orbital parameters, was accelerated by a factor of 10 . The chemical composition of the atmosphere was set to constant pre-industrial values throughout the simulation. KCM shows good agreement between simulated precipitation and observations for contemporary climate, as well as with the hydrological changes during the mid-Holocene (Khon et al., 2010).

\subsection{Analyses methods of model results}

Precipitation in monsoon regions has a strong seasonality and usually the summer (i.e. June-September) precipitation is taken to analyse changes in the monsoon intensity and to discuss rainfall variations in monsoon domains. We decided to use annual precipitation because we also include the East Asian monsoon region in which precipitation is not solely related to the summer season. Here, more than $30 \%$ of annual rainfall already falls during the months February-May (cf. Yihui and Zunja, 2008). Furthermore, reconstructions often integrate over a longer period and therefore an annual signal rather than a monthly or seasonal signal is recorded. For example plants (pollen proxy) can use moisture stored in the soil or lake level changes (various sedimentary proxies) record the annual balance. We do not want to exclude the pre-monsoon precipitation in East Asia from our analysis. In all other regions considered here, annual precipitation is highly correlated with summer precipitation. Therefore taking annual rainfall instead of summer rainfall does not affect the results in these regions. Moreover, defining a meaningful time period (in the form of months) for the summer monsoon season is difficult in palaeo-studies because the summer monsoon season may be variable over the time.

\subsubsection{Definition of the time-slices}

We compare the simulated climate of the mid-Holocene (6000 years ago, further referred to as $6 \mathrm{k}$ ) and pre-industrial time-slice (here referred to as $0 \mathrm{k}$ ). The results are based on climatological means of 120 years, i.e. 120 model years in the non-accelerated experiments and 12 model years in the 


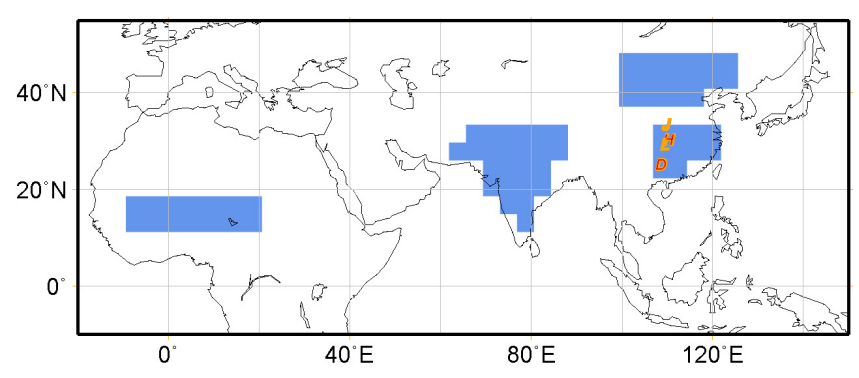

Figure 1. Definition of the different monsoon sub-regions used in this study (shaded) and the locations of caves in the East Asian monsoon region (letters) for which speleothem records exist, i.e. Dongge cave (D, 25.32 ${ }^{\circ} \mathrm{N}, 108.09^{\circ} \mathrm{E}$; Wang et al., 2005), Heshang Cave (H, $30.45^{\circ} \mathrm{N}, 110.42^{\circ} \mathrm{E}$; Hu et al., 2008), Lianhua Cave (L, $29.29^{\circ} \mathrm{N}$, $109.32^{\circ} \mathrm{E}$; Cosford et al., 2008), and Jiuxian Cave (J, 33.34 ${ }^{\circ} \mathrm{N}$, 109.6 $6^{\circ}$; Cai et al., 2010).

accelerated experiments. We are aware of the short period used to represent the accelerated simulations. Therefore, we calculated the statistical significance of the rainfall change using the student's $t$ test and only show results that are significant at the $95 \%$ level in the case of the non-accelerated simulations and significant at the $90 \%$ level in the case of the accelerated simulations. Thereby, the main aim is the assessment of the physical significance of the rainfall change.

Global fields of precipitation (in netCDF) for both time-slices are provided as supplementary material in the PANGAEA database (http://dx.doi.org/10.1594/PANGAEA. 837442).

\subsubsection{Inference of rainfall trends and comparison of regional time series}

The different sub-regions presented in this study (cf. Fig. 1) have been defined on the basis of the leading empirical orthogonal function (EOF) mode of the annual precipitation variations. For this purpose, the ensemble mean of the non-accelerated simulations (i.e. COSMOS, ECHO-G and PLASIM) has been standardised and detrended by a 500-year running mean. The EOF was calculated afterwards for the African, Indian and eastern Asian regions. The monsoon subsystems are selected based on the areas showing the highest loadings in the respective region. The East Asian monsoon domain is divided into two sub-regions, as it is commonly characterised by bipolar precipitation pattern in present-day observations, e.g. floods in the north, droughts in the south (e.g. Ding, 2007).

To test whether the different monsoon sub-systems are connected during pre-industrial times, we calculate the Pearson correlation coefficient based on the last 150 years of the annual mean precipitation time series (for interannual variability). For this purpose, the time series have been detrended by a 30 -year running mean. In addition, we calculate the Pearson correlation coefficients for decadal timescales based on the last 1000 years of the simulations. For this calculation, the time series have been filtered by a 10-year running mean and have been detrended by a 500-year running mean. Only the non-accelerated simulations are considered.

The rainfall trend series in the different sub-regions are based on 100-year running means to filter out interannual and interdecadal variability. Only the non-accelerated simulations have been considered since the accelerated simulations reveal a strong year-to-year variability. The significance of the trend is estimated by the signal-to-noise ratio. The time series are displayed as anomalies with respect to the last time-step representing the pre-industrial climate. To calculate the correlations among rainfall in the different monsoon sub-regions, the time series have been detrended by the 500 -year moving average of the annual time series. The rainfall trend series are provided as supplementary material in the PANGAEA database (http://dx.doi.org/10.1594/PANGAEA. 837442). Sliding correlations are performed for annual and decadal time series to assess if the teleconnections among the sub-systems are stable and if the regional monsoon teleconnections weakened or strengthened under varying orbital parameters.

Similarly, as for the time-slice results, the seasonal cycle in each sub-region has been calculated on climatological monthly means of 120 years.

\section{Results}

\subsection{Pre-industrial Asian and North African summer monsoon precipitation}

In order to get an overview of the representation of the preindustrial control climate in the different models we compare the simulated precipitation with data of the Global Precipitation Climatology Project (GPCP, 1979-2008, Adler et al., 2003). As the pre-industrial simulations have been performed with a $\mathrm{CO}_{2}$ concentration of $280 \mathrm{ppm}$, considerably lower than those observed for the present day, we expect small biases particularly in the strength of the monsoon system and precipitation amount resulting from the different $\mathrm{CO}_{2}$ levels.

\subsubsection{Evaluation of the annual precipitation pattern}

In general, the models are able to capture the summer monsoon circulation (see Appendix). They show similar discrepancies to the observed precipitation pattern, but the amplitude of the biases differs (Fig. 2). All models tend to overestimate annual precipitation in the East Asian monsoon region. This is particularly pronounced in the area between the Yangtze and Huanghe River in eastern China $\left(100-120^{\circ}\right.$ E, $\left.25-35^{\circ} \mathrm{N}\right)$ where pre-industrial annual precipitation exceeds the modern observations by more than $750 \mathrm{~mm}_{\text {year }}{ }^{-1}$ in most simulations and the ensemble mean.

In contrast, precipitation in the Indian monsoon region is highly underestimated in all models, particularly in 
Table 2. Absolute rainfall (mm year ${ }^{-1}$ ) in the ensemble mean Afro-Asian monsoon region (including land and ocean, cf. Fig. 2) during the pre-industrial period and in observations.

\begin{tabular}{rrrrrrrr}
\hline & GPCP & COSMOS & ECHO-G & PLASIM & COSMOSacc & KCM & ENSMEAN \\
\hline Rainfall $\left(\mathrm{mm} \mathrm{yr}^{-1}\right)$ & 941.7 & 1016.8 & 965.0 & 862.1 & 1052.2 & 998.2 & 978.9 \\
\hline
\end{tabular}
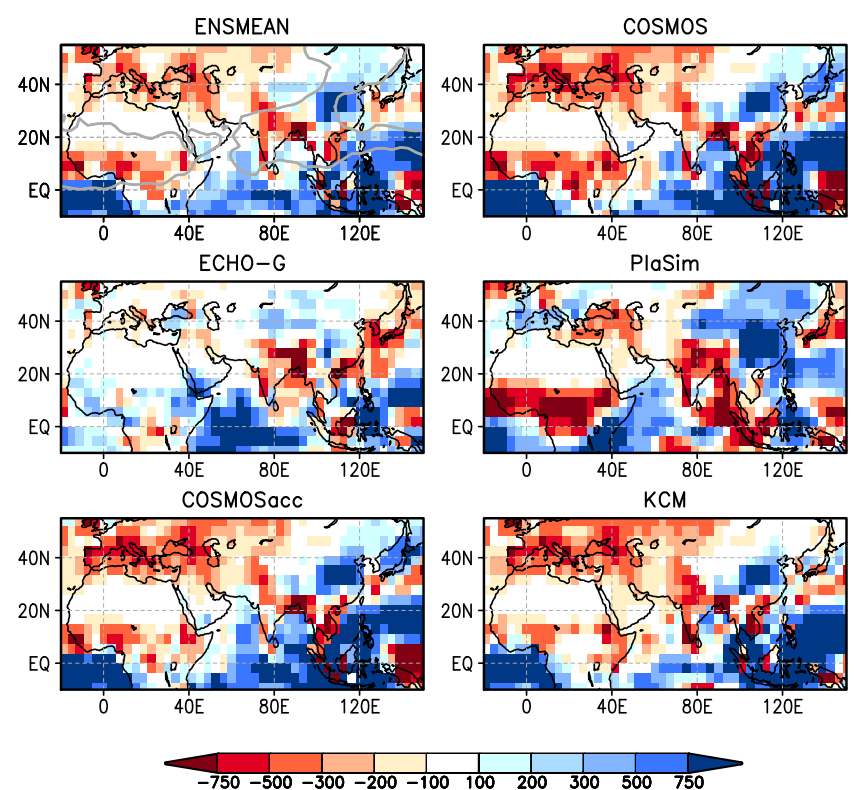

Figure 2. Biases in annual mean precipitation $\left(\mathrm{mm} \mathrm{year}^{-1}\right)$ between the different transient simulations (last 100 years, i.e. $0 \mathrm{k}$ ) and the modern observed climate, represented by the precipitation data of the Global Precipitation Climatology Project (GPCP, 1979-2008, Adler et al., 2003). The grey line in the plot of the ensemble mean marks the simulated pre-industrial Afro-Asian monsoon region, i.e the $55 \%$ isoline of the summer to annual precipitation.

Bangladesh, which exceeds by $-750 \mathrm{~mm}$ year $^{-1}$. With the exception of ECHO-G showing more precipitation than observed, all other models also underestimate precipitation by more than $300 \mathrm{~mm}_{\text {year }}{ }^{-1}$ in large parts of northern Africa. Above the tropical oceans, the models simulate considerably higher precipitation compared to observations. However, over these oceanic areas, precipitation observations are also afflicted with higher uncertainty.

Averaged over the entire ensemble mean monsoon region of North Africa and Asia (including oceanic areas, cf. Fig. 2), COSMOS, COSMOSacc and KCM simulate too much precipitation, and PLASIM too little precipitation. ECHO-G simulates similar rainfall as observed (cf. Table 2). To further quantify the biases between simulated and observed precipitation (here GPCP data), we chose a Taylor diagram (Fig. 3). This diagram is based on the climatological monthly mean precipitation values of each simulation and shows the pattern correlation of the simulated and observed precipitation and the centred root-mean-square difference of each simulation

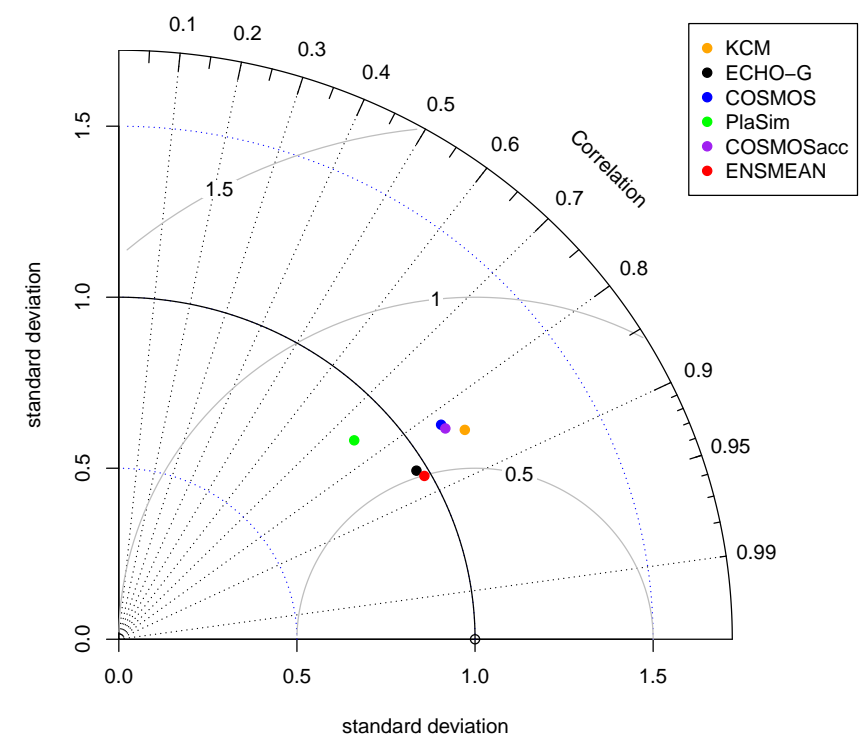

Figure 3. Taylor diagram showing the pattern correlation, normalised standard deviation and normalised root-mean-square error (grey circles) of the simulated precipitation in the different models (0k-time-slice) for the Afro-Asian monsoon region. Reference data set: GPCP, based on the years 1979-2008 (white dot).

to the observation. In addition, it displays the standard deviation in each data set comparing the amplitude of the temporal and spatial pattern variations. Overall, ECHO-G has a similar spatial and temporal variation as observed precipitation and agrees best with the observed precipitation pattern. PLASIM underestimates the variation slightly and shows the lowest correlation. KCM, COSMOSacc and COSMOS demonstrate a very similar skill for simulating the North African and Asian monsoon precipitation. Those models slightly overestimate the amplitude in pattern variation, but show a good pattern correlation. The ensemble mean reveals the best pattern correlation and also the highest agreement in terms of spatial and temporal variation.

\subsubsection{Evaluation of the seasonal precipitation cycle}

To assess the performance of the models with respect to the seasonal precipitation cycle, the simulated pre-industrial seasonal precipitation cycle for each sub-region is compared to the seasonal cycle derived from present-day GPCP data (Fig. 4): during the present-day times, the rainy season in the North African monsoon region (NAM) starts in March 

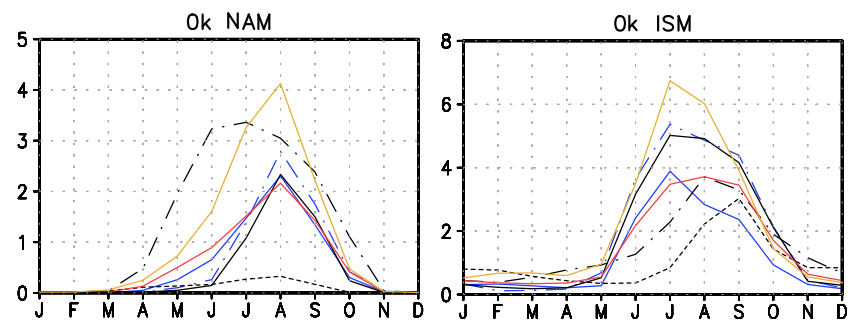

OK EASM

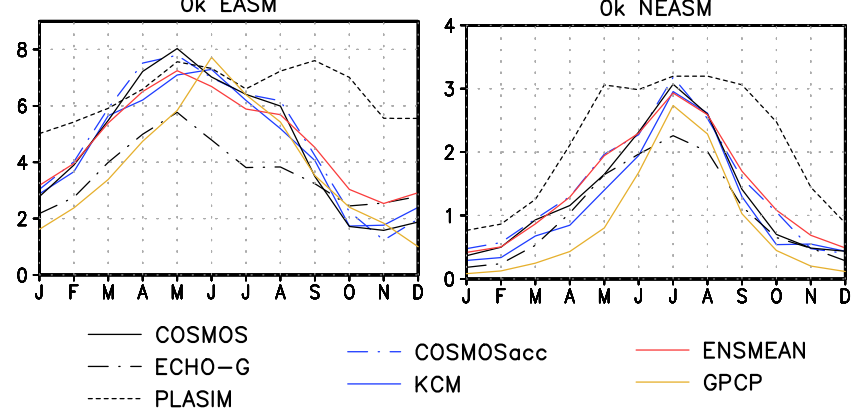

Figure 4. Simulated pre-industrial seasonal precipitation cycle compared to GPCP observational data (in $\mathrm{mm}_{\text {day }}{ }^{-1}$, based on the years 1979-2008), for different regions in the Afro-Asian monsoon domain, i.e. the North African monsoon region (NAM), Indian monsoon region (ISM), East Asian monsoon region (EASM), and the northern part of the East Asian monsoon region (NEASM). Please note the change in scale.

with rainfall continuously increasing to a rainfall peak of $4 \mathrm{~mm} \mathrm{day}^{-1}$ in August. Afterwards, precipitation declines until October. This seasonal cycle is simulated correctly by all models with the exception of ECHO-G which strongly overestimates precipitation during March-July, leading to peak rainfall by July. COSMOS, COSMOSacc and KCM simulate a similar seasonal cycle as observed, but underestimate rainfall rates during the entire rainy season (at summer peak by $1-2 \mathrm{~mm} \mathrm{day}^{-1}$ ). PLASIM reveals less than $0.5 \mathrm{~mm} \mathrm{day}^{-1}$ as the precipitation peak, which is a typical rainfall rate in (semi-) arid regions. Thus, with respect to maximum precipitation PLASIM does not identify the North African monsoon as a monsoon region.

The observed precipitation maximum over the Indian monsoon region (ISM) is reached during July following a very rapid increase of rainfall starting in May. None of the models captures this seasonal cycle: in PLASIM, the rainy season is very short. Precipitation starts to increase as late as July and does not peak until September. Rainfall rates are strongly underestimated during the entire rainy season. COSMOS, COSMOSacc and KCM reveal a similar monsoon season length as observed, but simulate a double-peak monsoon in July and September. However, these models also underestimate precipitation during the entire rainy season, particularly KCM, by up to $3 \mathrm{~mm} \mathrm{day}^{-1}$. Precipitation rates rise slower in ECHO-G than observed and the monsoon peak is shifted by one month to August. Rainfall rates are much lower compared to observations.

The observed seasonal precipitation cycle in the East Asian monsoon area (EASM) is different to the cycle in the tropical monsoon regions of Africa and India. Over this region, precipitation occurs during the entire year reaching rainfall rates of $1-2 \mathrm{~mm} \mathrm{day}^{-1}$ during winter and spring. Nevertheless, the temporal rainfall distribution reflects a monsoonal character with summer dominant rainfall and much higher precipitation rates in summer than in winter. Maximum rainfall is reached during June with approx. $6 \mathrm{~mm} \mathrm{day}^{-1}$. All models except PLASIM are able to simulate this seasonal cycle. However, winter and spring precipitation is strongly overestimated by $1-2 \mathrm{~mm} \mathrm{day}^{-1}$ leading to a rainfall peak by May. During summer, simulated rainfall rates are as observed in most models. ECHO-G simulates rainfall rates similar to those observed until May; afterwards precipitation rates decrease and are underestimated until September. PLASIM strongly overestimates the late summer, autumn and winter precipitation.

The observed seasonal precipitation cycle in the northern East Asian monsoon region (NEASM) is characterised by weak winter/spring rainfall rates and high summer rainfall rates, although much less than in the other parts of the monsoon domain, with a maximum precipitation rate of only $2.7 \mathrm{~mm} \mathrm{day}^{-1}$ in July. Most models capture the seasonal cycle, but slightly overestimate precipitation throughout the year by approx. $0.5 \mathrm{~mm} \mathrm{day}^{-1}$. ECHO-G simulates too little summer precipitation. Similarly, as for the East Asian monsoon region, PLASIM strongly overestimates precipitation during the entire year.

\subsubsection{Connectivity of the different sub-monsoon systems}

Table 3 shows the Pearson correlation coefficients for the annual and decadal (in brackets) precipitation time series of the different sub-regions considered here. Overall, only the COSMOS model shows a strong positive correlation among annual and decadal mean precipitation in the Indian and the North African monsoon $(r>0.8)$. In COSMOS, precipitation variability over these regions is also moderately correlated with precipitation over the northern part of the East Asian monsoon (annual: $r>0.6$ and decadal: $r>0.5$ ). These correlations stay at high levels throughout the entire 6000 years (not shown). For the other regions and in the other models, correlations are very weak and therefore change using different sliding windows. They remain mostly statistically non-significant (not shown). 
Table 3. Pearson correlation coefficients for the $0 \mathrm{k}$ rainfall time series, based on the last 150 years (1000 years) detrended by a 30 -year (500-year) running mean for annual (decadal) variability, for different monsoon sub-regions, i.e. the Indian monsoon region (ISM), North African monsoon region (NAM), East Asian monsoon region (EASM), and the northern part of the East Asian monsoon region (NEASM). Only the non-accelerated simulations have been used.

\begin{tabular}{lrrrr}
\hline COSMOS & ISM & NAM & EASM & NEASM \\
\hline ISM & $1.00(1.00)$ & - & - & - \\
NAM & $0.83(0.83)$ & $1.00(1.00)$ & - & - \\
EASM & $0.19(0.00)$ & $0.10(-0.01)$ & $1.00(1.00)$ & - \\
NEASM & $0.62(0.57)$ & $0.67(0.51)$ & $0.14(0.03)$ & $1.00(1.00)$ \\
\hline ECHO-G & ISM & NAM & EASM & NEASM \\
\hline ISM & $1.00(1.00)$ & - & - & - \\
NAM & $0.0(-0.12)$ & $1.00(1.00)$ & - & - \\
EASM & $-0.06(-0.12)$ & $-0.11(0.02)$ & $1.00(1.00)$ & - \\
NEASM & $0.12(0.09)$ & $0.06(0.00)$ & $0.22(0.26)$ & $1.00(1.00)$ \\
\hline PLASIM & ISM & NAM & EASM & NEASM \\
\hline ISM & $1.00(1.00)$ & - & - & - \\
NAM & $0.04(0.01)$ & $1.00(1.00)$ & - & - \\
EASM & $0.05(0.01)$ & $0.10(0.01)$ & $1.00(1.00)$ & - \\
NEASM & $0.10(0.11)$ & $0.08(0.08)$ & $0.01(0.09)$ & $1.00(1.00)$ \\
\hline
\end{tabular}

\subsection{Mid-Holocene climate}

\subsubsection{Changes in annual precipitation pattern}

Figure 5 shows the simulated mean annual precipitation difference between the mid-Holocene and pre-industrial. All models simulate an increase in precipitation in the North African and Indian monsoon regions during the midHolocene compared to the pre-industrial climate. In most models, these changes are connected with a shift in the ITCZ, indicated by the bipolar difference in precipitation pattern between ocean and land, particularly in northern Africa. This pattern is consistent with the increase in Northern Hemisphere summer insolation (Kutzbach, 1981). The largest changes occur in COSMOS and KCM revealing an increase in precipitation by more than $500 \mathrm{~mm} \mathrm{year}^{-1}$ in large parts of the monsoon region.

In the North African monsoon area, the simulated magnitude of precipitation change differs strongly among the models. ECHO-G reveals a relatively weak response to the insolation change with an increased mid-Holocene precipitation by less than $200 \mathrm{~mm}$ year $^{-1}$. PLASIM shows a significant rise in rainfall in the entirety of northern Africa including the Sahara, but the strongest changes are concentrated around the Equator. COSMOS, COSMOSacc and KCM indicate the strongest increase in precipitation in a broad area between the Equator and $20^{\circ} \mathrm{N}$ (by up to $400 \mathrm{~mm} \mathrm{day}^{-1}$ ). Regarding the precipitation increase in the Indian monsoon region, the models are in better agreement with each other. All models show a relatively strong response in a broad region extending from India to the central Tibetan Plateau (up
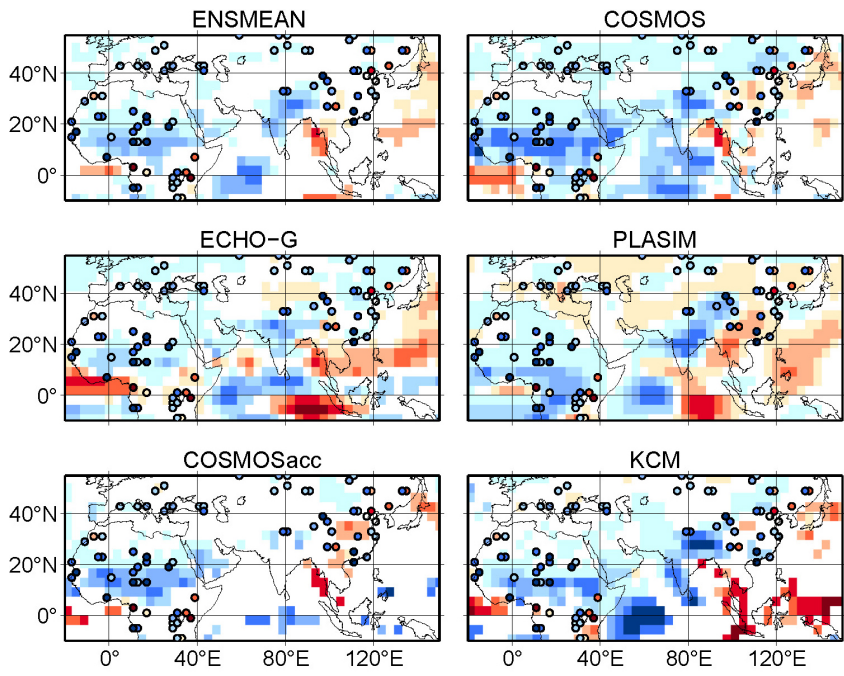

$$
-1000-500-300-200-100 \quad 0 \quad 100 \quad 200 \quad 300 \quad 500<
$$

Figure 5. Simulated mean annual precipitation difference (shaded, $\mathrm{mm}_{\text {year }}{ }^{-1}$ ) between mid-Holocene $(6 \mathrm{k})$ and pre-industrial climate $(0 \mathrm{k})$. Only significant values are shown, i.e. significant at the $95 \%$ level (student's $t$ test) for the non-accelerated experiments (ECHOG, COSMOS, PLASIM) and significant at the $90 \%$ level for the accelerated experiments (COSMOSacc, KCM). The ensemble mean (ENSMEAN) is defined as significant if all simulations agree in the sign of the precipitation change in the individual grid-boxes. The reconstructions of Bartlein et al. (2010) are additionally shown (dots, same legend as the simulated data).

to $650 \mathrm{~mm}$ year $^{-1}$ in KCM). COSMOSacc is the only model revealing no significant signal. 
In contrast to the increased North African and Indian monsoon rainfall during the mid-Holocene, the models tend to simulate less precipitation in the core regions of the East Asian monsoon domain. In PLASIM, precipitation decreases by approx. $200 \mathrm{~mm}$ year $^{-1}$ in Indochina, eastern China, and over the western Pacific Ocean. COSMOS and COSMOSacc reveal a significant reduction of precipitation only in centraleastern China (up to $300 \mathrm{~mm}_{\text {year }}{ }^{-1}$ ). In ECHO-G, the decrease in precipitation is limited to the Indochinese Peninsula and the western Pacific. The strong inter-model discrepancies concerning the rainfall change in the East Asian monsoon region lead to a non-significant signal in the ensemble mean.

Figure 5 additionally shows pollen-based precipitation reconstructions (Bartlein et al., 2010) plotted on top of the simulated precipitation changes. Overall, the simulated rainfall difference between the mid-Holocene and the pre-industrial agree well with reconstructions which reveal substantially increased mid-Holocene precipitation at most sites. However, the models tend to underestimate the precipitation change, particularly in northern Africa and eastern China.

\subsubsection{Change in the seasonal precipitation cycle}

Figure 6 shows the simulated change in the seasonal precipitation cycle between the mid-Holocene and the pre-industrial for the different monsoon sub-regions.

For the mid-Holocene time-slice, the models reveal a consistent picture regarding the shape of change in the North African seasonal precipitation cycle (NAM), but they vary regarding the amplitude. Precipitation is increased from June to November revealing the strongest signal in August (PLASIM, ECHO-G and KCM) and September (COSMOS, COSMOSacc). The most intense response is shown in COSMOS with a peak signal of up to $3.5 \mathrm{~mm} \mathrm{day}^{-1}$. The weakest response occurs in PLASIM with maximum values of $0.5 \mathrm{~mm} \mathrm{day}^{-1}$ at most. The maximum precipitation difference between the mid-Holocene and the pre-industrial timeslice in the North African monsoon region coincides with the present-day monsoon season peak, suggesting a strong intensity change of the North African monsoon and not a postponement of the monsoon season.

Similar to the North African monsoon region, all models simulate increased precipitation during summer and autumn (May-November) in the Indian monsoon region (ISM) during the mid-Holocene with maximum precipitation values in August (PLASIM, KCM and ECHO-G) and September (COSMOS, COSMOSacc). PLASIM and KCM reveal the strongest response with 2.5 and $2.2 \mathrm{~mm} \mathrm{day}^{-1}$ at most, respectively. In the other models, the magnitude of rainfall change is similar with maxima ranging from 1.2 to $1.6 \mathrm{~mm} \mathrm{day}^{-1}$.

The simulated seasonal precipitation change in the East Asian monsoon region (EASM) from the mid-Holocene to the pre-industrial is very different to the change in the tropical monsoon domain because precipitation reacts to the in-
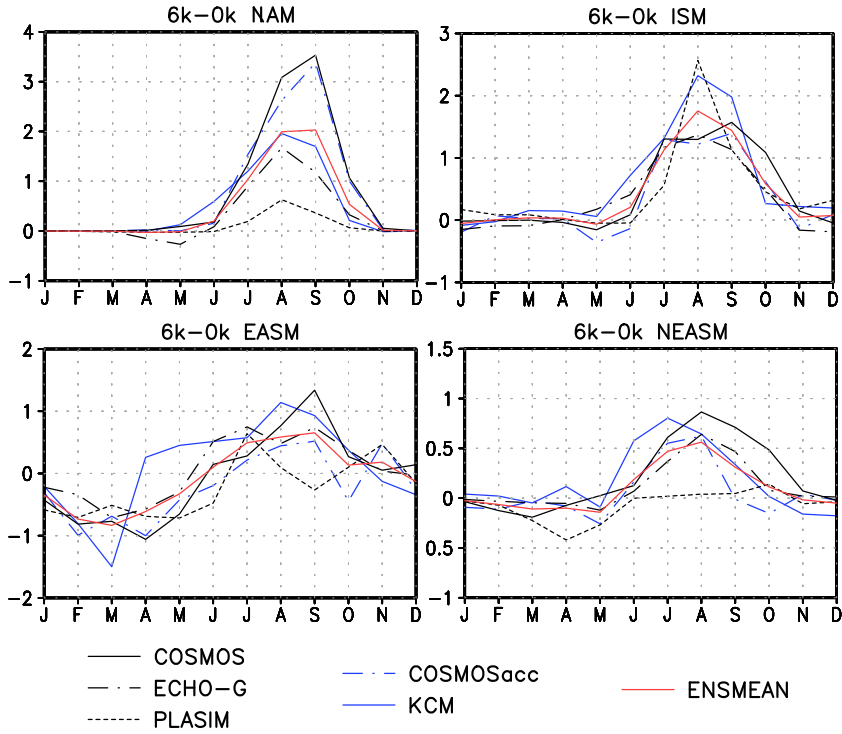

Figure 6. Simulated change in the seasonal precipitation cycle between mid-Holocene and pre-industrial climate $\left(\mathrm{mm} \mathrm{day}^{-1}\right)$ for different regions in the Afro-Asian monsoon domain, i.e. the North African monsoon region (NAM), Indian monsoon region (ISM), East Asian monsoon region (EASM), and the northern part of the East Asian monsoon region (NEASM). Please note the change in scale.

solation forcing throughout the year. In most models, winter and spring precipitation are substantially reduced by up to $1 \mathrm{~mm} \mathrm{day}^{-1}\left(1.5 \mathrm{~mm} \mathrm{day}^{-1}\right.$ in KCM). Summer monsoon rainfall is increased by $0.5 \mathrm{~mm} \mathrm{day}^{-1}$ (PLASIM) to $1.3 \mathrm{~mm} \mathrm{day}^{-1}$ (COSMOS) at most. The strongest enhancement of rainfall occurs in July (ECHO-G, PLASIM), August (KCM) and September (COSMOS).

Most models simulate slightly decreased precipitation in the northern East Asian monsoon region (NEASM) during the mid-Holocene winter and spring. This signal is particularly pronounced in PLASIM $\left(0.5 \mathrm{~mm} \mathrm{day}^{-1}\right.$ at most). During summer, rainfall increases in all models by up to $0.8 \mathrm{~mm} \mathrm{day}^{-1}$ (COSMOS). Maximum precipitation is reached in July (KCM) or August. PLASIM shows a very weak response to changes in the summer insolation and simulates only slightly more precipitation during October.

The seasonal precipitation change indicates that the annual rainfall signals in the African and Indian monsoon region are mostly related to the increased summer monsoon precipitation at $6 \mathrm{k}$. In contrast, the decreased mid-Holocene rainfall in parts of the East Asian monsoon area (cf. Fig. 5) cannot be explained by summer monsoon changes. With the exception of PLASIM, precipitation is increased in most parts of the East Asian monsoon domain during the mid-Holocene summer monsoon season (not shown) revealing that the decrease in precipitation is related to changes in the pre-monsoon season as previously pointed out in Dallmeyer et al. (2013). In this region, the Holocene summer monsoon signal is over- 
Table 4. Pearson correlation coefficients for the rainfall time series in the different monsoon sub-regions, i.e. the Indian monsoon region (ISM), North African monsoon region (NAM), East Asian monsoon region (EASM), and the northern part of the East Asian monsoon region (NEASM). The time series have been detrended by a 500-year moving average before calculating the correlation coefficients. Only the non-accelerated simulations have been used.

\begin{tabular}{lrrrr}
\hline COSMOS & ISM & NAM & EASM & NEASM \\
\hline ISM & 1.00 & - & - & - \\
NAM & 0.38 & 1.00 & - & - \\
EASM & -0.08 & -0.02 & 1.00 & - \\
NEASM & 0.50 & 0.36 & 0.19 & 1.00 \\
\hline ECHO-G & ISM & NAM & EASM & NEASM \\
\hline ISM & 1.00 & - & - & - \\
NAM & 0.31 & 1.00 & - & - \\
EASM & -0.19 & -0.02 & 1.00 & - \\
NEASM & 0.12 & 0.20 & 0.17 & 1.00 \\
\hline PLASIM & ISM & NAM & EASM & NEASM \\
\hline ISM & 1.00 & - & - & - \\
NAM & 0.27 & 1.00 & - & - \\
EASM & -0.08 & 0.03 & 1.00 & - \\
NEASM & -0.11 & 0.09 & 0.17 & 1.00 \\
\hline
\end{tabular}

compensated by the pre-monsoon signal. In comparison with the reconstructions of Bartlein et al. (2010), which show increased precipitation in East Asia, COSMOS and ECHO-G may overestimate the decreased pre-monsoon precipitation at $6 \mathrm{k}$.

\subsection{Rainfall trend}

Figure 7 shows the evolution of rainfall in the different submonsoon regions based on the non-accelerated climate simulations. For the North African region, all models show a statistically significant ( $>99 \%$ ) negative rainfall trend ranging from $40 \mathrm{~mm} / 6000$ years (PLASIM) to $280 \mathrm{~mm} / 6000$ years (COSMOS). The trends are relatively linear, but all models suggest a stronger trend in the first 4000 years, i.e. from 6 to $2 \mathrm{k}$, than in the last 2000 years of the simulations. Both ECHO-G and COSMOS reveal periods of long-lasting dry and wet phases interrupting the general trend. The nonlinearity of the trends is consistent with changes in orbital forcing, i.e. the rate of change in the decline of northern hemispheric summer insolation is larger in the mid-Holocene compared to the late Holocene.

For the Indian monsoon region, all models indicate a similar decreasing trend of $130-160 \mathrm{~mm} / 6000$ years. This trend is statistically significant (>99\%) and linear, but superimposed by several long-lasting dry and wet periods. For instance, COSMOS, and to a minor extent ECHO-G, reveal a prominent long-lasting dry period around $2 \mathrm{k}$. PLASIM simulates less precipitation compared to pre-industrial times
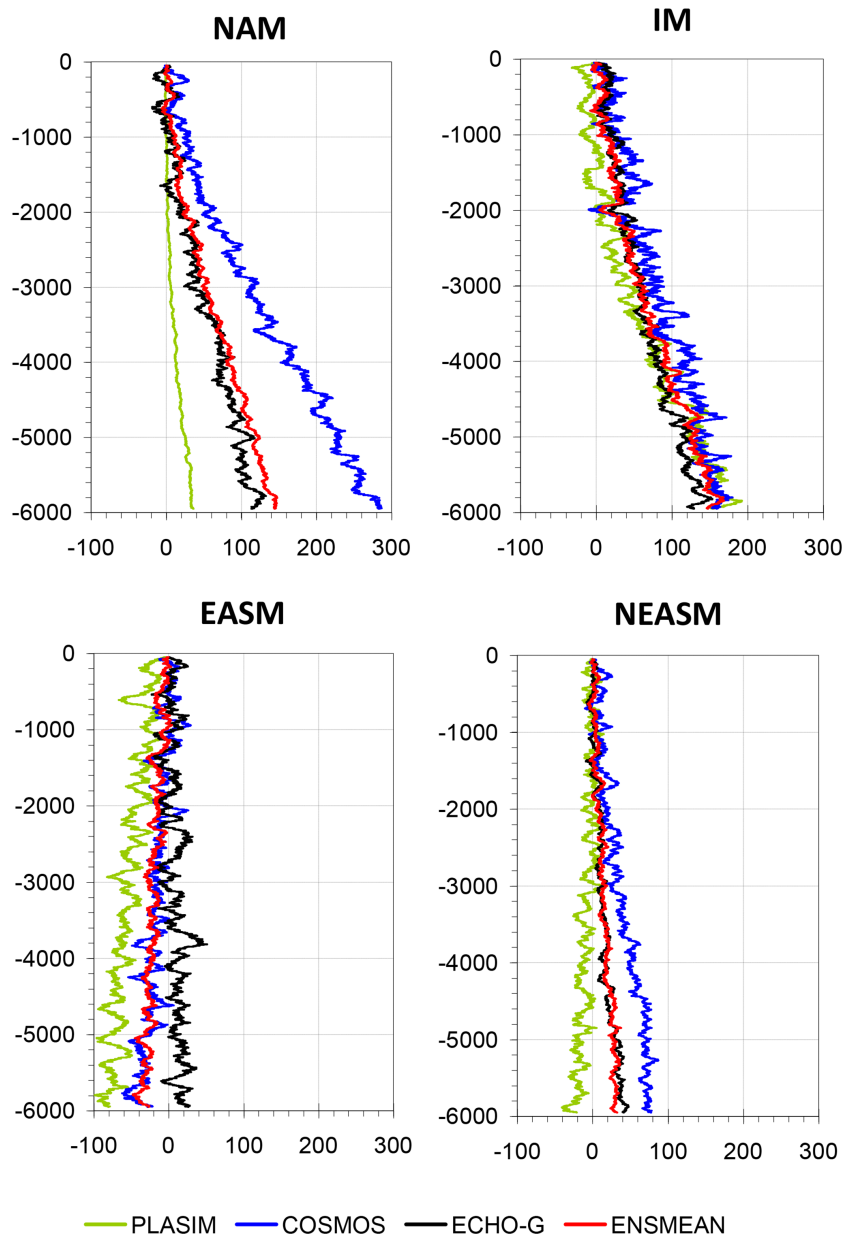

Figure 7. Simulated rainfall trend (100-year running mean, in mm year $^{-1}$ ) in different sub-regions of the Afro-Asian monsoon domain, displayed as an anomaly to the last time-step representing the pre-industrial climate. The regions are: the North African monsoon region (NAM), Indian monsoon region (ISM), East Asian monsoon region (EASM), and the northern part of the East Asian monsoon region (NEASM).

for some periods in the last 2000 years. The evolution of the precipitation signal simulated by COSMOS shows moderate positive correlation with the precipitation variability over northern Africa $(r=+0.38$, Table 4$)$. In ECHO-G and PLASIM, Indian rainfall is only weakly correlated with rainfall over northern Africa $(r=+0.31$ and $r=+0.27$, respectively).

The models disagree regarding the sign of the precipitation trend over the East Asian monsoon region. COSMOS and PLASIM indicate a slightly increasing trend during the Holocene of $20 \mathrm{~mm} / 6000$ years (significant at the $90 \%$ level) and $80 \mathrm{~mm}_{\text {year }}{ }^{-1}$ (significant at the $99 \%$ level), respectively. In contrast, ECHO-G reveals a slightly decreasing trend of $20 \mathrm{~mm} / 6000$ years (significant at the $95 \%$ level). The trends are generally linear, but the area is characterised 
by stronger variability than for the other monsoon regions. At 3.8 and $2.3 \mathrm{k}$ ECHO-G indicates periods with strongly increased precipitation. Most models indicate no correlation between the rainfall over eastern China and over India or northern Africa, only ECHO-G reveals a weak negative correlation with the precipitation variability over India $(r=-0.19)$.

For the northern part of the East Asian monsoon region, ECHO-G and COSMOS show a highly significant decreasing trend since the mid-Holocene $(40 \mathrm{~mm} / 6000$ years and $80 \mathrm{~mm} / 6000$ years, respectively). PLASIM suggests an increasing precipitation trend. While the rainfall trend is linear in ECHO-G and PLASIM, precipitation stays relatively constant until $4.5 \mathrm{k}$ in COSMOS and decreases linearly afterwards. The rainfall variability over the northern part of the East Asian monsoon region simulated by COSMOS is moderately correlated with precipitation over northern Africa $(r=+0.36)$ and India $(r=+0.5)$ and weakly correlated with precipitation in the southern part of the East Asian monsoon region $(r=+0.19)$. ECHO-G also shows weak correlation between the precipitation variability over these areas.

\section{Discussion}

\subsection{Performance of the models}

Recent studies have identified that climate models reveal large deficits in representing the mean precipitation distribution, seasonal cycle, and interannual variability of monsoon systems (Kang et al., 2002; Randall et al., 2007; Boo et al., 2011). Common state-of-the-art atmosphere models show poor reproducibility of recent variations in the monsoon circulation and precipitation (Zhou et al., 2009 and references therein). Reasons for this might be the large internal variability of monsoons (Krishnamurti et al., 2006) or deficits in parameterisations of the convective processes in the tropics.

The climate models used in this study overestimate annual precipitation in the subtropical East Asian monsoon region and underestimate annual rainfall in the tropical monsoon regions. However, with few exceptions they are able to capture the seasonal precipitation cycle in the different monsoon sub-systems. With the exception of COSMOS, all models reveal no significant link between interannual and decadal rainfall variations in the sub-monsoon regions at pre-industrial times. The strong connection of the North African, Indian and northern East Asian monsoon region may be related to the El Niño-Southern Oscillation variability, which is very prominent in the COSMOS model.

The simulated mid-Holocene climate agrees well with results from other global climate modelling studies, e.g. the analyses undertaken within the Paleoclimate Modelling Intercomparison Project (PMIP, e.g. Zhao and Harrison, 2011; Wang et al., 2010) showing generally a wetter mid-Holocene summer climate in the boreal monsoon regions. With the exception of PLASIM, all the models considered here simulate an increase in summer precipitation within the AfroAsian monsoon domain (not shown) leading to an increased annual precipitation in most monsoon sub-regions. This is also in line with reconstructions. In eastern Asia only, annual rainfall decreases during the mid-Holocene in nearly all simulations, disagreeing with the reconstructed precipitation from cave records in this domain (cf. Sect. 4.2). In all regions, the amplitude of precipitation change is too weak compared with reconstructions. This result is also shown in other model intercomparison studies (e.g. PMIP; Zhao and Harrison, 2011). It is possible that reconstructions may overestimate the Holocene precipitation change as there is some degree of uncertainty in the reconstructions.

As the systematic model biases (e.g. biases related to parameterisations) are probably similar for the pre-industrial time-slice and the rest of the transient simulations, we assume that biases in precipitation do not affect the general credibility of results inferred in this study as long as only differences in the pre-industrial time-slice are analysed. Nevertheless, on a local scale, the seasonal biases in precipitation may affect the simulated Holocene climate.

\subsection{Global vs. regional monsoon on centennial to millennial timescale}

In recent years, the concept of "global monsoon" has been introduced, interpreting monsoon systems as part of one global-scale atmospheric overturning circulation in the tropics and subtropics implying a connection between the regional monsoon systems and an in-phase behaviour of all monsoons on annual timescales (Trenberth et al., 2000). Whether the global monsoon concept can be applied to past climates and variability on longer timescales is not yet clear (Trenberth et al., 2000). Although recent palaeo-studies support the global monsoon hypothesis (Cheng et al., 2012; Liu et al., 2012), there are many arguments for a rather regional behaviour and at least regional characteristics of the different monsoon systems in modern observations and palaeorecords. For the Holocene, several studies report an asynchronous rainfall trend in different parts of the Asian monsoon region (An et al., 2000; Maher, 2008) and an out-ofphase evolution of the Indian and East Asian monsoon (Maher and $\mathrm{Hu}, 2006$; Wang et al., 2010). Some records suggest an abrupt end of the humid period in the North African monsoon area (e.g. deMenocal et al., 2000), whereas other records suggest a gradual decrease in rainfall during the Holocene (e.g. Kropelin et al., 2008; Francus et al., 2013).

The transient simulations used in this study reveal continuously decreasing precipitation in nearly all sub-monsoon regions since the mid-Holocene. This agrees with most reconstructions and underscores that the orbitally induced insolation change determines the Holocene rainfall trend pattern. However, compared to the reconstructions of Bartlein et 


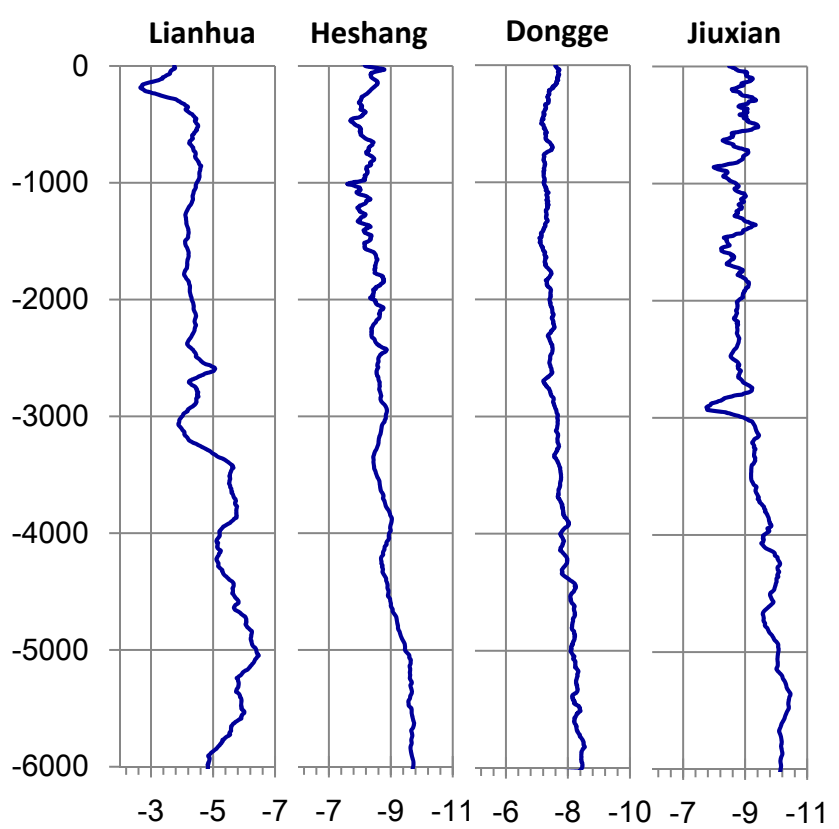

Figure 8. Reconstructed speleothem oxygen isotope records $\left(d^{18} \mathrm{O}\right.$, per mil) taken from different caves in the East Asian monsoon region (cf. Fig. 1), i.e.: Lianhua Cave $\left(29.29^{\circ} \mathrm{N}, 109.32^{\circ} \mathrm{E}\right.$; Cosford et al., 2008), Heshang Cave (30.45 ${ }^{\circ} \mathrm{N}, 110.42^{\circ} \mathrm{E}$; Hu et al., 2008), Dongge cave $\left(25.32^{\circ} \mathrm{N}, 108.09^{\circ} \mathrm{E}\right.$; Wang et al., 2005), and Jiuxian Cave (J, 33.34 ${ }^{\circ} \mathrm{N}, 109.6^{\circ} \mathrm{E}$; Cai et al., 2010).

al. (2010), the amplitude of precipitation change is underestimated by the models. Abrupt changes such as those recorded in the North African monsoon region cannot be seen in the model results, but the simulations were performed in a coarse resolution and we chose a relatively large area representing the North African monsoon eventually smoothing out drastic changes. On a local scale, abrupt changes might be possible (e.g. Bathiany et al., 2012). Furthermore, important processes such as ice-sheet dynamics or vegetation related processes are not or only partly represented in the models. The proxy-based reconstructions might not reflect the precipitation change only.

In eastern China, most models suggest an increase in precipitation during the Holocene that is not supported by the speleothem records in this region (Fig. 8), but in other (e.g. pollen-based) reconstructions (cf. Wang et al., 2010 and references therein; Dallmeyer et al., 2013). Recent studies pointed out that cave records in eastern China may not reflect absolute rainfall nor summer rainfall, but rather represent the moisture source (Maher, 2008; Cheng et al., 2012 and references therein; Maher and Thompson, 2012), and thus indicate the relative strength of the involved circulation systems (East Asian monsoon, Indian monsoon and Westerly wind system). A weakening of the Indian monsoon during the Holocene and the associated reduction in its inland penetration into eastern China may have strengthened the influence of the East Asian monsoon (oceanic source) trans-
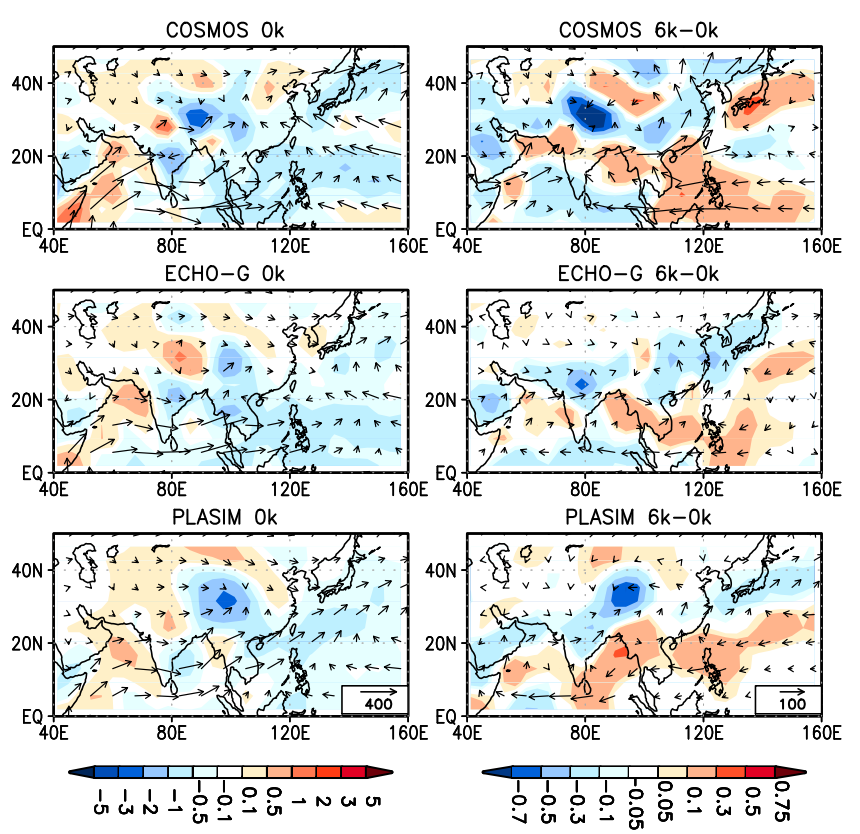

Figure 9. Simulated pre-industrial (summertime) vertically integrated moisture flux (vector, $\mathrm{kg} \mathrm{ms}^{-1}$ ) and its convergence (shaded, $10 \times 10^{-5} \mathrm{~kg} \mathrm{~m}^{-2} \mathrm{~s}$ ), i.e. convergence $=$ blue (atmospheric moisture sink), divergence $=$ red (atmospheric moisture source), as well as simulated change in vertically integrated moisture flux (vector, $\mathrm{kg} \mathrm{ms}^{-1}$ ) and its convergence (shaded, $10 \times 10^{-5} \mathrm{~kg} \mathrm{~m}^{-2} \mathrm{~s}$ ) between mid-Holocene and pre-industrial times.

porting less depleted air from the Pacific to the caves (Maher and Thompson, 2012). Indeed, the transient simulations reveal an enhanced vertically integrated moisture flux from the Indian summer monsoon region into eastern China during the mid-Holocene (see Fig. 9). However, they do not agree with each other regarding the modern moisture flux: COSMOS shows a strong summer moisture transport from the Pacific to eastern China during pre-industrial times, i.e. a strong East Asian summer monsoon. In ECHO-G, the vertically integrated moisture flux is dominated by the Westerlies. In PLASIM, the Indian monsoon is still prominent in eastern China at $0 \mathrm{k}$. The misinterpretation of the cave records may be one possible reason for the discrepancies between the model results and the reconstructions. However, most models overestimate pre-industrial spring precipitation in eastern China. The increasing rainfall trend during the Holocene mainly results from a strong increase of spring precipitation which overcompensates the reduction in summer monsoon precipitation. This signal may not be realistic for the entire region. Due to the coarse resolution, the models can probably simulate the large-scale response to the Holocene insolation forcing, but not specific regional or local details (cf. Dallmeyer et al., 2013).

Overall, the transient simulations modify the global monsoon hypothesis, at least on centennial timescales. Although the Holocene long-term rainfall trend is synchronous in most 

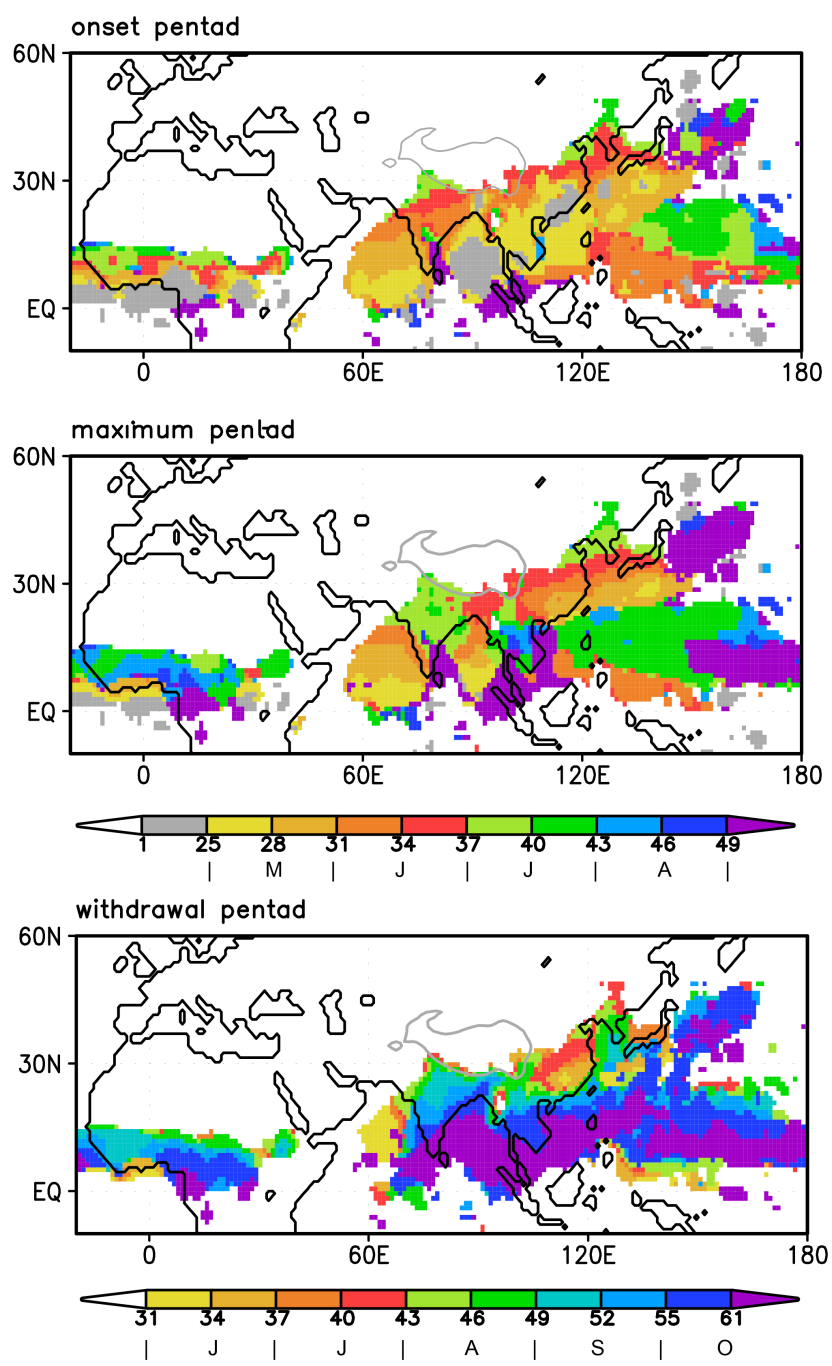

Figure 10. Pentad of monsoon onset, maximum monsoon rainfall, and withdrawal based on the observational data set of the Climate Prediction Centre (CMAP, 1979-2008, Xie and Arkin, 1997), calculated following the criteria of Wang and LinHo (2002).

monsoon sub-systems, the centennial variability within the 6000 -year-long time series is very different. In this context, the model results rather suggest a differentiation between tropical and sub-tropical monsoon systems. The North African and the Indian monsoon (both tropical monsoons) are correlated in all models, i.e. both monsoon systems show a similar response to the insolation forcing, which can be explained by their strong connection to shifts in the global Intertropical Convergence Zone. The East Asian monsoon (sub-tropical) is not robustly correlated with the tropical monsoon systems in the models. Only COSMOS reveals a connection between the rainfall in northern Africa, India, and the northern part of the East Asian monsoon region (NEASM). In this model, the moisture flux from India towards northern China is enhanced during the mid-Holocene, probably explaining the strong connectivity of these monsoon sub-systems (cf. Fig. 9).

\subsection{Effect of seasonality on the Holocene precipitation trend}

Figure 10 displays the pentad of monsoon onset and withdrawal as well as the month of rainfall peak in the AfroAsian monsoon region based on the observational data set of the Climate Prediction Centre (CMAP, 1979-2008, Xie and Arkin, 1997). Both have been calculated according to Wang and Linho (2002) on the basis of the relative pentad mean rainfall, i.e. the difference between the pentad mean rainfall rate and the January mean rainfall rate. The period in which the relative mean pentad rainfall exceeds $5 \mathrm{~mm} \mathrm{day}^{-1}$ is defined as a monsoon season.

In comparison to local observations, the onset is slightly too early (cf. Wang and LinHo, 2002); the withdrawal and peak are well presented in CMAP. The figure reveals large differences in seasonality among the individual monsoon sub-systems, summarised in Table 5. The Indian monsoon season starts during June and moves to its northern position during early July. Maximum precipitation rates are reached during July. The North African monsoon breaks out (end of June-July) and peaks (July-August) slightly later. Both monsoon sub-systems retreat during September-October. In contrast, the East Asian monsoon season starts (May-early June), peaks (June) and ends (July-August) very early in the summer season so that the East Asian monsoon season is short compared to the tropical summer monsoons. To analyse the influence of these differences in seasonality between the monsoon sub-systems on the Holocene precipitation trend, the analysis is extended to the early Holocene (further referred to as $9 \mathrm{k}$ ).

The precession of the Equinoxes leads to shifts in the date of Perihelion, i.e. the date of smallest distance between Sun and Earth. Every 1900 years, Perihelion is shifted by one month (Ruddiman, 2008). At present day, Perihelion occurs early in January, leading to rather warm winters and mild summers in the Northern Hemisphere. During the early Holocene (9k), the date of Perihelion was in August and in the mid-Holocene ( $6 \mathrm{k}$ ) by the end of September. This change in Perihelion determines the time of maximum insolation change compared to the present day. Thus, maximum insolation change coincides with the peak rainy season in northern Africa and India during the early Holocene and coincides with the late monsoon season in the mid-Holocene. For the East Asian monsoon system, maximum insolation occurs at the end of the rainy season during the early Holocene and after the rainy season in the mid-Holocene. How do these zonally uniform insolation changes affect the sub-monsoon regions that have such different seasonal cycles?

Considering only insolation variations as forcing for Holocene precipitation changes, several hypotheses can be proposed: 
Table 5. Month of onset, peak and withdrawal in the different monsoon regions.

\begin{tabular}{llll}
\hline Region & Onset & Peak & Withdrawal \\
\hline Indian monsoon & June/July & July & September/October \\
North African monsoon & End of June/July & July/August & September/October \\
East Asian monsoon & May-early June & June & July/August \\
\hline
\end{tabular}

1. Hypothesis: the increase in summer monsoon precipitation compared to the pre-industrial period is larger at $9 \mathrm{k}$ than at $6 \mathrm{k}$, because the maximum insolation change at $9 \mathrm{k}$ is larger and in phase with the present-day monsoon season.

2. Hypothesis: the shift in maximum insolation change from summer at $9 \mathrm{k}$ towards autumn in $6 \mathrm{k}$ should lead to an intensification of the summer monsoon at $9 \mathrm{k}$ and a prolongation of the monsoon season at $6 \mathrm{k}$ in comparison to the pre-industrial period.

3. Hypothesis: the East Asian monsoon does not benefit as much as the tropical monsoon systems from the enhancement of summer insolation change in the early and mid-Holocene because the maximum insolation increase occurs after the present-day monsoon season.

In the following, these hypotheses are discussed based on the transient climate simulation performed in the Kiel Climate Model (KCM), because this is the sole simulation in the transient simulations considered here that covers the early Holocene and has been undertaken in a comprehensive global climate model. Since we only analyse monthly precipitation data, we define the onset of the summer monsoon in the model by the month in which rainfall rate increases strongly. Accordingly, we define the end of the monsoon season by the last month in which the rainfall decreases drastically. We are aware of the impreciseness of this definition, but it does not affect the conclusions drawn in this section.

Reconstructions are rather indicative of annual accumulated precipitation; seasonal variations cannot be resolved. Therefore we cannot directly utilise reconstructions to prove these hypotheses. We assume that differences in the seasonality among the sub-monsoon systems may affect the strength of the rainfall response to the orbital variations and may therefore lead to systematic differences in the Holocene rainfall maximum. This would underline the third hypothesis. For this purpose, the synthesis of the reconstruction drawn by Wang et al. (2010) is analysed regarding the timing of the wettest period during the Holocene.

\subsubsection{What does the transient simulation performed in the KCM show?}

The impact of insolation on past monsoon climates has been analysed intensively with climate models before. However, only few studies concentrate on the aspect of dissimilar seasonality in different sub-monsoon systems and on how the response to orbitally induced insolation forcing might be affected by this seasonality. Braconnot and Marti (2003) point out that the response of the monsoon circulation depends on the timing of maximum summer insolation change and that the timing of the seasonal cycle may explain the leads and lag times between insolation forcing and monsoonal reconstructions. Marzin and Braconnot (2009) showed that the Indian and African monsoon are most enhanced when the insolation forcing is in phase with the seasonal development of the monsoon system. According to their simulation, the Indian summer monsoon is prolonged and stronger during the early Holocene than during the mid-Holocene. In contrast, the North African monsoon is comparably enhanced at both time-slices. In the following, we analyse the effect of insolation changes on different monsoon systems based on the KCM simulation because this simulation also covers the early Holocene. The change in seasonal precipitation cycle between 9, 6, 3 and $0 \mathrm{k}$ can be seen in Fig. 11. The seasonal cycle of insolation change at 30 and $50^{\circ} \mathrm{N}$ as well as the meridional gradient in insolation change $\left(30^{\circ} \mathrm{N}-30^{\circ} \mathrm{S}\right)$ are shown in Fig. 12.

Confirming the first hypothesis, the increase in monsoon precipitation over the North African and Indian monsoon regions is higher at $9 \mathrm{k}$ than at $6 \mathrm{k}$ and higher at $6 \mathrm{k}$ than at $3 \mathrm{k}$. The precipitation signal over northern Africa in the model KCM follows the change in interhemispheric insolation gradient (e.g. $30^{\circ} \mathrm{N}-30^{\circ} \mathrm{S}$ ) with a lag time of about one month, probably reflecting the dependence of the monsoon system on the South Atlantic Ocean and the interhemispheric energy gradient. This insolation gradient anomaly is positive during spring and strongly increases in March at $9 \mathrm{k}$ and in April at $6 \mathrm{k}$ leading to an earlier onset of the monsoon season over northern Africa during the early Holocene than the midHolocene, taking the month of strongly increasing precipitation as the onset of the rainy season. The insolation gradient anomaly at $9 \mathrm{k}$ exceeds the anomaly at $6 \mathrm{k}$ during the entire monsoon season until August. This (+1 month lag) is also the period in which the precipitation difference with the preindustrial is larger at $9 \mathrm{k}$ than at $6 \mathrm{k}$ in KCM. In September, the insolation gradient becomes negative at 9 and $6 \mathrm{k}$. This results in a fast decline of the rainfall signal in the KCM simulation and similar endings of the monsoon season during both periods. This result does not therefore support the second hypothesis of a postponed rainy season at $6 \mathrm{k}$. However, 


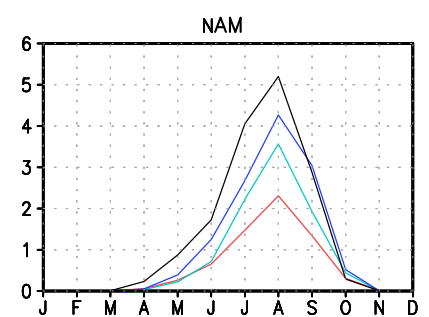

ISM

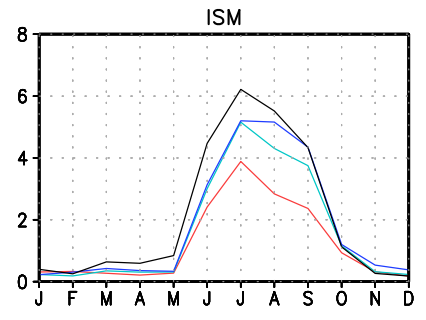

EASM

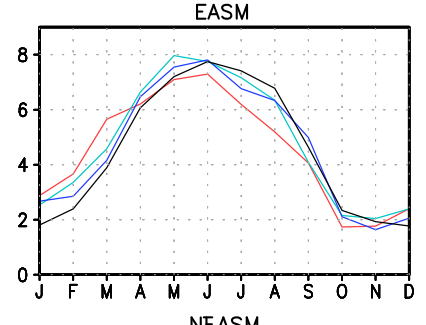

NEASM
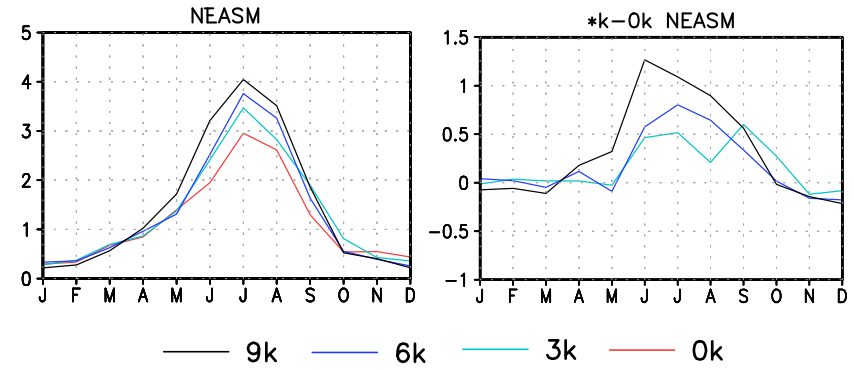

$6 \mathrm{k}$
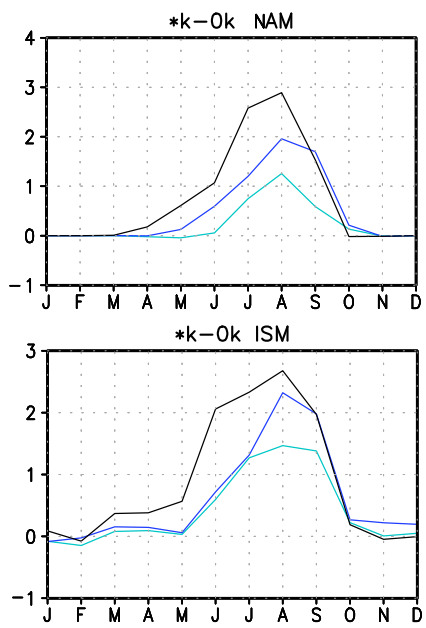

*k-Ok EASM

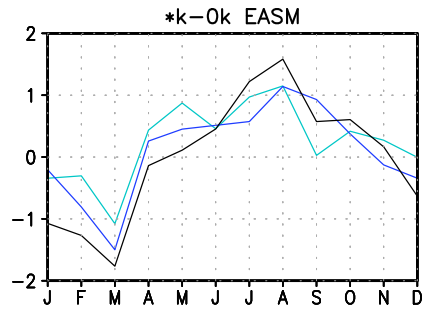

$\mathrm{Ok}$

Figure 11. Simulated seasonal precipitation cycle $\left(\mathrm{mm} \mathrm{day}^{-1}\right)$ for different time-slices $(9,6,3$, and $0 \mathrm{k})$ and the different monsoon subregions in the Afro-Asian monsoon domain, as well as the change in seasonal precipitation cycle $\left(\mathrm{mm} \mathrm{day}^{-1}\right.$ ) between $9 / 6 / 3$ and $0 \mathrm{k}$, based on the transient Holocene simulation performed in KCM. The regions are: the North African monsoon region (NAM), Indian monsoon region (ISM), East Asian monsoon region (EASM), and the northern part of the East Asian monsoon region (NEASM). Please note the change in scale.

over northern Africa as well as over India, the largest change in precipitation between 9 and $6 \mathrm{k}$ simulated by the KCM occurs in the first half of the monsoon season, while the precipitation difference between 6 and $3 \mathrm{k}$ particularly accumulates during peak time and afterwards. This is in accordance with the insolation forcing.

According to $\mathrm{KCM}$, the onset of the rainy period over the Indian monsoon region is similar for all time-slices considered here. Thus, the precipitation variability is neither fully determined by the change in the insolation gradient nor by the insolation change on the Northern Hemisphere (here $30^{\circ} \mathrm{N}$ ). During the early Holocene and mid-Holocene,

Insolation 50N, difference to $0 \mathrm{k}$

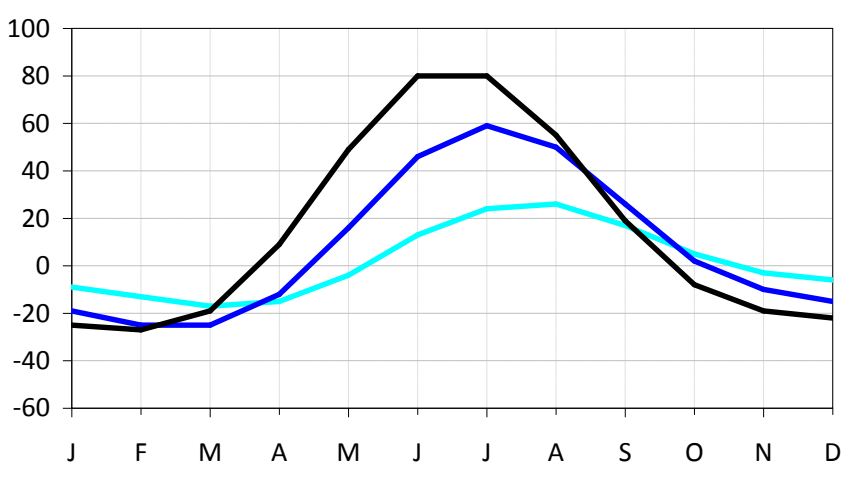

Insolation 30N, difference to $0 \mathrm{k}$

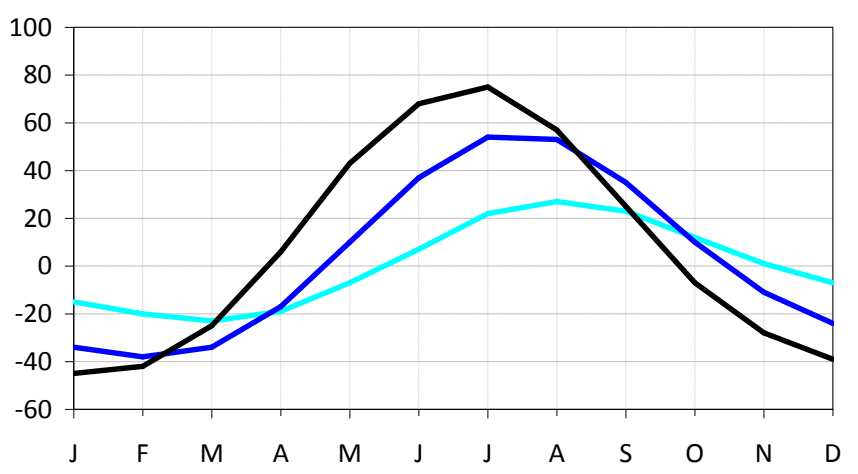

30N-30S Insolation, difference to $0 \mathrm{k}$

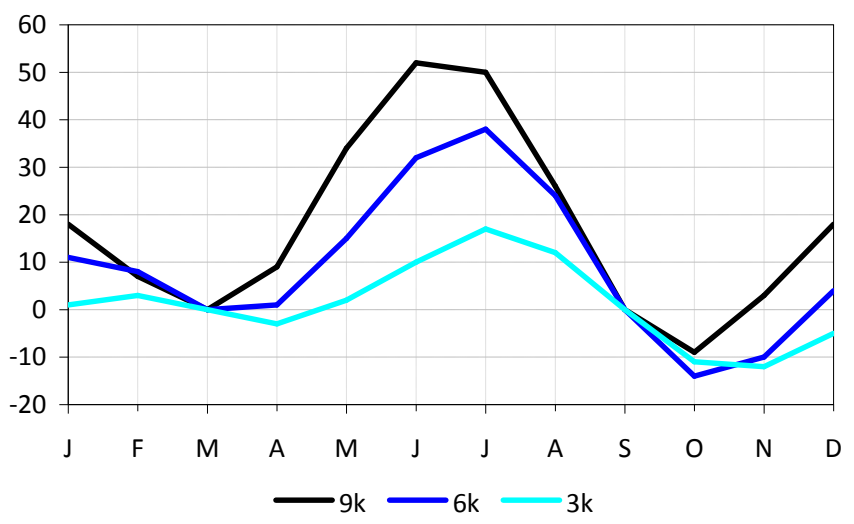

Figure 12. Solar incoming radiation at $50^{\circ} \mathrm{N}, 30^{\circ} \mathrm{N}$ and insolation gradient between $30^{\circ} \mathrm{N}$ and $30^{\circ} \mathrm{S}$ for different time-slices $(9,6$ and $3 \mathrm{k})$ as an anomaly to present-day insolation $(0 \mathrm{k})$, in $\mathrm{W} \mathrm{m}^{-1}$.

the increase in precipitation is more pronounced over northern Africa $(+140$ and $+73 \%$ compared to the pre-industrial time-slice, Table 6$)$ than over India (+93 and $+50 \%)$. This is probably also related to the strong dependence of the North African monsoon on the interhemispheric insolation gradient, which is more favourably changed with respect to an en- 
Table 6. Annual mean relative precipitation difference (\%) between 6 and $0 \mathrm{k}$ for each simulation, averaged over the different monsoon sub-regions. For KCM, the precipitation differences between 9 and $6 \mathrm{k}$ and 9 and $0 \mathrm{k}$ are also shown.

\begin{tabular}{lrrrrrrr}
\hline & ECHO-G & COSMOS & PLASIM & & KCM & & COSMOSacc \\
\cline { 2 - 8 } & $6-0 \mathrm{k}$ & $6-0 \mathrm{k}$ & $6-0 \mathrm{k}$ & $9-0 \mathrm{k}$ & $6-0 \mathrm{k}$ & $9-6 \mathrm{k}$ & $6-0 \mathrm{k}$ \\
\hline NAM & 23.7 & 173.3 & 100.0 & 139.6 & 92.5 & 24.5 & 130.4 \\
NEASM & 10.6 & 16.2 & -3.3 & 26.7 & 14.7 & 10.5 & 6.4 \\
EASM & 1.7 & -1.3 & -3.6 & -0.2 & 2.4 & -2.6 & -4.6 \\
ISM & 23.4 & 23.9 & 44.2 & 72.5 & 50.0 & 15.0 & 17.0 \\
\hline
\end{tabular}
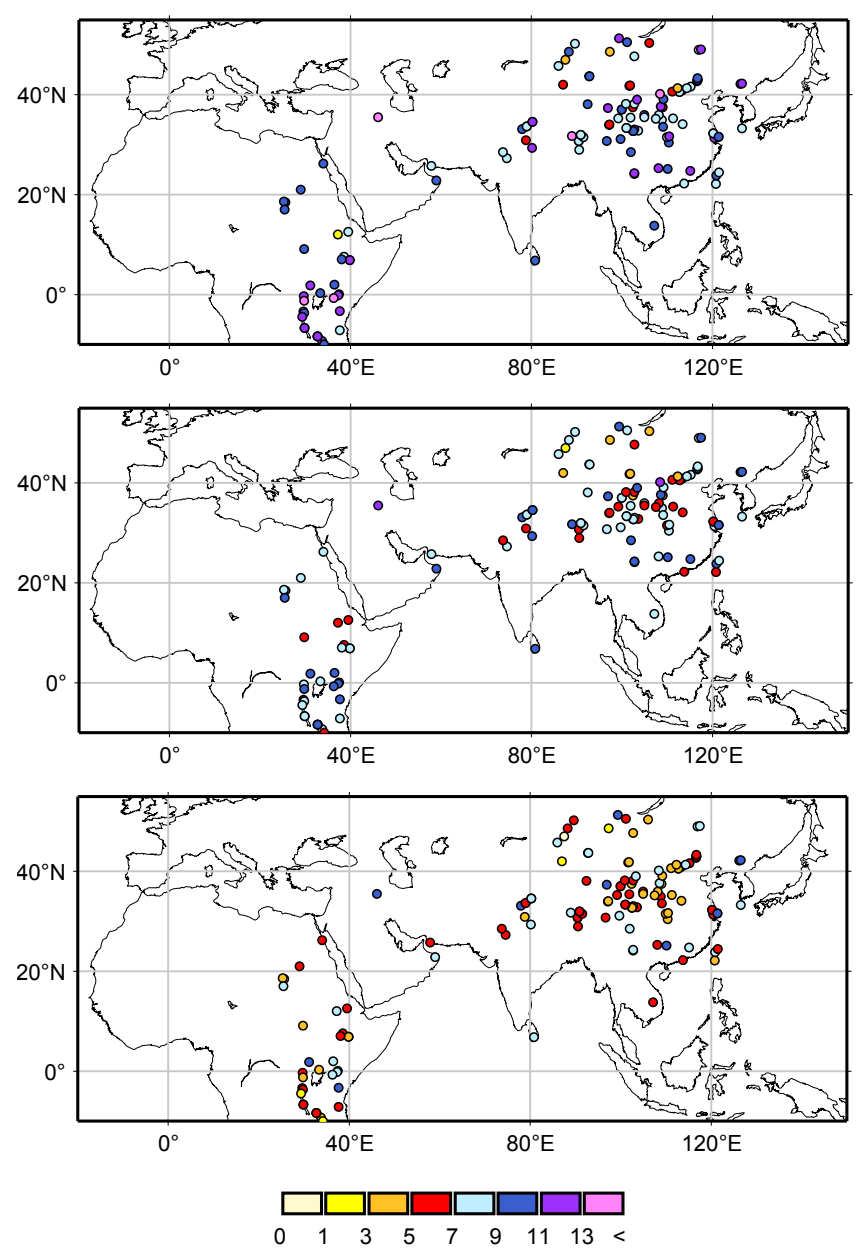

Figure 13. Reconstructed start (upper panel), mid and end (lower panel) time of the wettest period during the Holocene (in ky before present), based on the synthesis of records by Wang et al. (2010).

hancement of monsoon systems than the insolation change at $30^{\circ} \mathrm{N}$ alone.

The East Asian monsoon region experiences minor rainfall changes compared to the tropical monsoon systems, confirming the third hypothesis. The annual averaged precipitation amount is similar for 9 and $0 \mathrm{k}$. During the mid-Holocene, rainfall is slightly increased by $2 \%$. However, the $9 \mathrm{k}$ sig- nal is an intensification of the $6 \mathrm{k}$ signal, i.e. the decrease in spring precipitation is more pronounced at $9 \mathrm{k}$ than at $6 \mathrm{k}$, balancing the higher increase in summer precipitation at $9 \mathrm{k}$. Besides the strength of the rainfall change and the decreasing precipitation during spring reflecting the Holocene insolation change on the Northern Hemisphere, the simulated change in annual rainfall cycle in the East Asian monsoon region reveals no clear relationship to the seasonal insolation change. This indicates that other factors might also be relevant. For instance, the climate in eastern Asia may be more sensitive to ocean feedbacks due to the special land-ocean configuration (Maher, 2008). The large meridional extent and the dependence of the East Asian monsoon on the western Pacific subtropical high probably makes the East Asian monsoon more constrained by the ocean thermal inertia (Wang et al., 2003). Furthermore, eastern Asia is more affected by the Westerly wind circulation than the Indian or North African monsoon region.

Overall, KCM shows an impact of the differences in seasonality on the seasonal distribution of the Holocene precipitation change, but does not indicate a systematic effect of the seasonality on the timing of the Holocene rainfall optimum. Sensitivity experiments will help to further investigate the physical mechanisms of the different responses in the subsystems of the Afro-Asian monsoon system.

\subsubsection{What do reconstructions show?}

Fig. 13 shows the start, mid-point and end of the wettest period in the last 15000 years based on the reviewed reconstructions by Wang et al. (2010), but extended by reconstructions from Africa and newly published records from East Asia. The reconstructions so far cover only the Asian monsoon region and eastern Africa, but not the North African monsoon area where no comparable synthesis of reconstructions exists.

The reconstructions reveal no systematic differences in rain optimum between the sub-monsoon domains, but regional tendencies: over eastern Africa, the wettest period starts early in the Holocene or even before (9-13 k) at most sites. The end of the optimum is variable, ranging from $1-11 \mathrm{k}$. On average, the wettest periods last from $11-5 \mathrm{k}$ in southern hemispheric eastern Africa and from $10-6 \mathrm{k}$ in 
northern hemispheric eastern Africa. Few records exist for the Indian region and they do not agree regarding the start and end of the Holocene rainfall optimum. For the Indian monsoon area as defined in this study, the wettest period begins at $9 \mathrm{k}$ and ends at $7 \mathrm{k}$, on average. The Holocene rainfall optimum over south-eastern China starts early, i.e. between 9 and $13 \mathrm{k}$ at most sites. However, several caves records are located in this region that may indicate the moisture source rather than the absolute rainfall (cf. Sect. 4.2). Thus, these records may portray the strong Indian monsoon. In the northern part of eastern China, the start of the wettest period is very different, but several sites indicate a late rainfall optimum (between 3 and $7 \mathrm{k}$ ). The wettest period terminates between 3 and $5 \mathrm{k}$ for many regions. Over the East Asian monsoon region defined for this study (EASM), the rain optimum period lasts from 10 to $6 \mathrm{k}$, on average. In the northern part of the East Asian monsoon region (NEASM), the wettest period starts at $8 \mathrm{k}$ and ends at $6 \mathrm{k}$, on average.

This synthesis of reconstructions, with respect to the timing of the Holocene rainfall maximum, reveals that single records cannot be used to characterise the monsoon sub-systems and to draw conclusions regarding the timing of maximum monsoon intensity. Furthermore, the reconstructions do not indicate an effect of seasonality on the Holocene rainfall trends and are thus in line with the model results. However, the synthesis of reconstruction by Wang et al. (2010) is based on various proxies. Even though all may record information on moisture changes, each proxy at each site may record a unique signal with respect to precipitation/moisture seasonality and amount.

\section{Summary and conclusions}

Monsoon circulations are primarily driven by seasonal and latitudinal differences in incoming solar radiation. Recent observations indicate an in-phase variability of all boreal monsoon systems on annual and partly even decadal timescales leading to the establishment of the global monsoon concept. Whether this concept can be applied to past monsoon variability is still an open question (Trenberth et al., 2000). Reconstructions reveal large differences in the palaeomonsoon evolution and suggest, for example, that the different seasonality of the monsoon systems is responsible for the asynchronous monsoon precipitation change.

The Holocene rainfall trend and variability in different sub-areas of the Afro-Asian monsoon region has been analysed on the basis of five transient climate model simulations covering the last 6000 years. These simulations have been performed within a wide spectrum of coupled atmosphereocean-(vegetation) models forced with prescribed changes in Earth's orbital parameters during the Holocene. To extend the analysis to the early Holocene and to investigate changes in the seasonal cycle of the monsoon systems, the transient simulation undertaken with the Kiel Climate Model (KCM, Park et al., 2009) has been used, covering the last 9500 years. Our analysis addresses the following questions: can these climate models capture the reconstructed rainfall trend in the different parts of the Afro-Asian monsoon region? Do the monsoon sub-systems respond synchronously to the Holocene insolation forcing, supporting the global monsoon hypothesis? Is the Holocene precipitation response to the insolation forcing affected by the miscellaneous seasonality in the different monsoon sub-systems?

\section{a. Model evaluation:}

- The models represent the modern precipitation pattern, but they tend to underestimate annual precipitation in the tropical monsoon regions, i.e. northern Africa (by more than $300 \mathrm{~mm}^{-}$year $^{-1}$ ) and India (by more than $750 \mathrm{~mm} \mathrm{year}^{-1}$ ), and overestimate annual rainfall over eastern China (by more than $750 \mathrm{~mm}$ year $^{-1}$ ).

- The pattern of precipitation change is similar to the reconstructions of Bartlein et al. (2010), showing an increased annual precipitation in most parts of the monsoon region in the mid-Holocene compared to pre-industrial times. However, the amplitude of the precipitation signal is too weak in the models.

- In some parts of the East Asian monsoon region, precipitation is decreased by $200-300 \mathrm{~mm}$ year $^{-1}$ during the mid-Holocene. This decrease in precipitation is not in line with most reconstructions, as these show lower mid-Holocene precipitation rates only at a few sites in eastern Asia.

- The seasonal cycle of precipitation is captured by most models over most areas with only a few exceptions. The simulations reveal two modes of seasonal precipitation change between the mid-Holocene and the pre-industrial period: in the tropical monsoon systems, precipitation is increased during the entire monsoon season but unchanged during the rest of the year. In contrast, the East Asian monsoon region experiences a decrease of precipitation during spring and an increase of precipitation during summer, partly compensating each other.

- COSMOS is the only model showing a link between the interannual and decadal rainfall variations in the Indian and North African monsoon region as well as the northern part of the East Asian monsoon region. This correlation is nearly constant throughout the Holocene revealing that these teleconnections are not affected by orbital variations in the model.

b. Synchronous vs. asynchronous response to Holocene insolation forcing: 
- Over the North African and Indian monsoon region all models simulate a negative Holocene precipitation trend. Rainfall also declines in the northern part of the East Asian monsoon region in all simulations with the exception of PLASIM.

- In the core region of the East Asian monsoon domain, precipitation increases during the Holocene. Here, only ECHO-G suggests a negative rainfall trend. The increasing trend is not in line with cave records. However, recent studies have pointed out that the cave records in eastern Asia may have been misinterpreted so far, not portraying absolute precipitation but rather the source region of the moisture (e.g. Maher and Thompson, 2012).

- The rainfall trend is similar in most sub-monsoon regions, but the centennial rainfall variations are only partly correlated. COSMOS reveals a moderate correlation between the precipitation signal over India and northern Africa $(r=+0.38)$, as well as the northern part of the East Asian monsoon region and India $(r=+0.5)$ and northern Africa $(r=+0.36)$. In this model, the moisture flux from India to north-eastern China is intensified at $6 \mathrm{k}$, probably explaining the strong connection between these regions. The other models suggest only weak correlations between the tropical sub-monsoon systems and no correlation at all with the East Asian monsoon.

c. Seasonality

- In line with the Holocene insolation forcing, the increase in precipitation compared to pre-industrial times over northern Africa and India is larger during the early Holocene than during the midHolocene (25 and $15 \%$, respectively).

- The strongest insolation change in the early and mid-Holocene occurs during the present-day tropical monsoon season peak (July-August), but at the end of the rainy season in the East Asian monsoon region. Therefore, the tropical monsoon systems react more sensitively to the insolation forcing than the East Asian monsoon.

- The change in seasonal precipitation over northern Africa strongly follows the meridional interhemispheric insolation gradient (here: $30^{\circ} \mathrm{N}-$ $30^{\circ} \mathrm{S}$ ) with a lag time of about one month. Precipitation is predominantly increased during summer (by up to $3.5 \mathrm{~mm} \mathrm{day}^{-1}$ ) and unchanged in the cold season (November-March). The differences in the timing of the strong insolation increase during spring leads to the onset of the North African monsoon one month earlier at $9 \mathrm{k}$ than at $6 \mathrm{k}$. The withdrawal is similar for both periods.
- The Indian monsoon rainfall change in KCM is neither determined by the interhemispheric insolation gradient nor the northern hemispheric insolation change. The onset and withdrawal of the rainy season is not affected by the insolation forcing. Similar to the North African monsoon region, the precipitation predominantly increases during summer with maximum rainfall rates of $2.6 \mathrm{~mm} \mathrm{day}^{-1}$ at $9 \mathrm{k}$ and $2.2 \mathrm{~mm} \mathrm{day}^{-1}$ at $6 \mathrm{k}$.

- The East Asian monsoon experiences minor rainfall changes during the Holocene because the insolation-induced increase in precipitation during the summer monsoon season is counter-balanced by a decrease in spring precipitation. The annual averaged rainfall sum is similar for $9 \mathrm{k}$ and for preindustrial times and increased by $2 \%$ during the mid-Holocene. The change in East Asian monsoon precipitation is only partly driven by the Holocene insolation signal. Our results show that this monsoon sub-system is probably also affected by other factors, for instance related to ocean-atmosphere interactions or processes related to the Westerly wind circulation.

- The synthesis of reconstructions for the Asian and eastern African area reveals no systematic differences in rainfall optimum between the submonsoon systems during the Holocene as they rather indicate locally inhomogeneous rainfall changes. However, averaged over the different records, they show the tendency of an early occurrence of the wettest period in eastern Africa (10$6 \mathrm{k})$, southern China (10-6k), and India (9-7k). The rainfall optimum in the northern part of the East Asian monsoon region starts and ends slightly later (8-6k).

The transient simulations modify the global monsoon concept, at least on centennial to millennial timescales. Although the rainfall trend is similar in most sub-monsoon regions, the rainfall variations are only partly correlated. Our results suggest a coupling between the tropical monsoon systems of India and northern Africa on centennial timescales, but an independent evolution of the East Asian monsoon during the Holocene. Besides the seasonal distribution of the rainfall change that is determined by the present-day seasonal cycle in the different monsoon sub-systems, the transient simulation reveals no systematic influence of the different seasonality on the Holocene precipitation change. This is in line with the reconstructions analysed in this study. These do not support the hypothesis of an effect of the seasonality on the Holocene rainfall history. They suggest rather that single records should not be used to characterise the rainfall change for the entirety of the monsoon sub-systems and that one cannot draw conclusions regarding the timing of maximum monsoon intensity using single records only. 


\section{Appendix A: Evaluation of the monsoon flow $(850 \mathrm{hPa}$ wind field $)$}

The summer-half year (MJJASO) wind field in the AfroAsian monsoon region shows a number of characteristic features (Fig. A1): the strongest large-scale systems are the south-east and north-east trade winds, the circulation around the vast subtropical highs, i.e. the Azores high and the western Pacific subtropical high, and the strong Indian monsoon circulation that is canalised at the Ethiopian highlands in the so-called Somali jet, reaching wind speeds of approx. $10 \mathrm{~m} \mathrm{~s}^{-1}$ in the summer mean. The North African monsoon circulation is only weakly pronounced due to the inclusion of May and October in the averaging period.
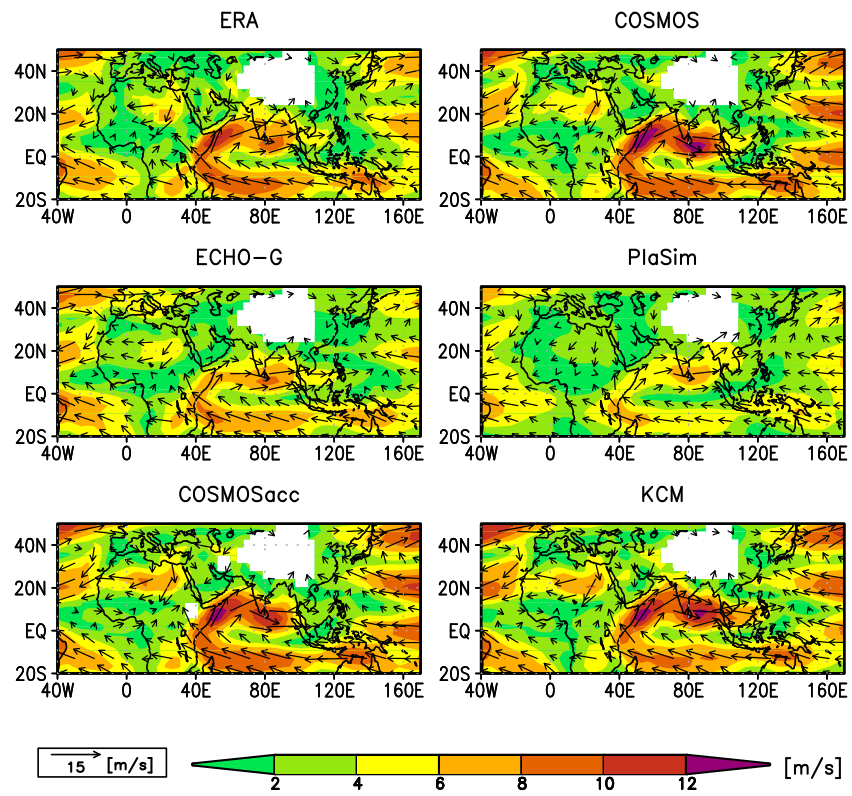

Figure A1. Simulated pre-industrial ( $0 \mathrm{k})$ atmospheric circulation in $850 \mathrm{hPa}$ (vector, $\mathrm{m} \mathrm{s}^{-1}$ ) and wind intensity (shaded, $\mathrm{m} \mathrm{s}^{-1}$ ) during the summer season (MJJASO). Compared to the ERA40 reanalysis data (ERA, 1979-1999, Uppala et al., 2005). No wind vectors are shown were the model orography exceeds the $850 \mathrm{hPa}$-level.
All models are able to simulate the summer circulation pattern in $850 \mathrm{hPa}$, but they differ in strength of the simulated large-scale circulation systems. COSMOS, COSMOSacc and KCM overestimate the Somali jet and the circulation over the western Pacific leading to an Indian and East Asian summer monsoon circulation that is too strong. In contrast, the African monsoon is weaker and the north-east trade winds above the Sahara are stronger than observed in these models. ECHO-G and particularly PLASIM underestimate the Indian and the African monsoon flows. The East Asian monsoon circulation on land is similar to the observed in ECHO-G and overlapped by the Indian monsoon flow in PLASIM. These results show that, at least in the Indian monsoon region, the deficits in simulated rainfall are not related to biases in the large-scale circulation pattern. 
Acknowledgements. We acknowledge P. J. Bartlein for providing reconstructions of the mid-Holocene rainfall. We thank S. Bathiany (MPI) and two anonymous reviewers for constructive comments that improved the manuscript. This research is part of the priority program INTERDYNAMIK funded by the German Research Foundation (DFG). This study also contributes to the Cluster of Excellence CliSAP (Integrated Climate System Analysis and Prediction) funded by the German Federal Government and the German States. Supplementary data are available at http://dx.doi.org/10.1594/PANGAEA.837442.

The service charges for this open-access publication have been covered by the Max Planck Society.

Edited by: A. Paul

\section{References}

Adler, R. F., Huffman, G. J., Chang, A., Ferraro, R., Xie, P. P., Janowiak, J., Rudolf, B., Schneider, U., Curtis, S., Bolvin, D., Gruber, A., Susskind, J., Arkin, P., and Nelkin, E.: The version-2 global precipitation climatology project (gpcp) monthly precipitation analysis (1979-present), J. Hydrometeorol., 4, 1147-1167, 2003.

An, Z. S., Porter, S. C., Kutzbach, J. E., Wu, X. H., Wang, S. M., Liu, X. D., Li, X. Q., and Zhou, W. J.: Asynchronous holocene optimum of the east asian monsoon, Quaternary Sci. Rev., 19, 743-762, 2000.

Bartlein, P. J., Harrison, S. P., Brewer, S., Connor, S., Davis, B. A. S., Gajewski, K., Guiot, J., Harrison-Prentice, T. I., Henderson, A., Peyron, O., Prentice, I. C., Scholze, M., Seppä, H., Shuman, B., Sugita, S., Thompson, R. S., Viau, A. E., Williams, J., and Wu, H.: Pollen-based continental climate reconstructions at 6 and 21 ka: A global synthesis, Clim. Dynam., 37, 775-802, 2010.

Bathiany, S., Claussen, M., and Fraedrich, K.: Implications of climate variability for the detection of multiple equilibria and for rapid transitions in the atmosphere-vegetation system, Clim. Dynam., 38, 1775-1790, 2012.

Berger, A. L.: Long-term variations of daily insolation and quaternary climatic changes, J. Atmos. Sci., 35, 2362-2367, 1978.

Boo, K. O., Martin, G., Sellar, A., Senior, C., and Byun, Y. H.: Evaluating the East Asian monsoon simulation in climate models, J. Geophys. Res., 116 D01109, doi:10.1029/2010JD014737, 2011.

Braconnot, P. and Marti, O.: Impact of precession on monsoon characteristics from coupled ocean atmosphere experiments: changes in Indian monsoon and Indian ocean climatology, Mar. Geol., 201, 23-34, 2003.

Brovkin, V., Raddatz, T., Reick, C. H., Claussen, M., and Gayler, V.: Global biogeophysical interactions between forest and climate, Geophys. Res. Lett. 36, L07405, doi:10.1029/2009GL037543, 2009.

Cai, Y., Tan, L., Cheng, H., An, Z., Edwards, R. L., Kelly, M. J., Kong, X., and Wang, X.: The variation of summer monsoon precipitation in central China since the last deglaciation, Earth Planet. Sci. Lett., 291, 21-31, 2010.

Caley, T., Malaizé, B., Revel, M., Ducassou, E., Wainer, K., Ibrahim, M., Shoeaib, D., Migeon, S., and Marieu, V.: Orbital timing of the indian, east asian and african boreal monsoons and the concept of a "global monsoon", Quaternary Sci. Rev., 30, 3705-3715, 2011.

Cheng, H., Sinha, A., Wang, X., Cruz, F. W., and Edwards, R. L.: The global paleomonsoon as seen through speleothem records from asia and the americas, Clim. Dynam., 39, 1045-1062, 2012.

Cosford, J., Qing, H., Eglington, B., Mattey, D., Yuan, D., Zhang, M., and Cheng, H.: East Asian monsoon variability since the mid-Holocene recorded in a high-resolution, absolute-dated aragonite speleothem from eastern China, Earth Planet. Sci. Lett., 275, 296-307, 2008.

Dallmeyer, A., Claussen, M., Wang, Y., and Herzschuh, U.: Spatial variability of holocene changes in the annual precipitation pattern: A model-data synthesis for the asian monsoon region, Clim. Dynam., 40, 2919-2936, 2013.

deMenocal, P., Ortiz, J., Guilderson, T., Adkins, J., Sarnthein, M., Baker, L., and Yarusinsky, M.: Abrupt onset and termination of the african humid period: Rapid climate responses to gradual insolation forcing, Quaternary Sci. Rev., 19, 347-361, 2000.

Ding, Y. H.: The variability of the Asian summer monsoon, J. Meteorol. Soc. Japan B, 85, 21-54, 2007.

Feudale, L. and Kucharski, F.: A common mode of variability of african and indian monsoon rainfall at decadal timescale, Clim. Dynam., 41, 243-254, 2013.

Fischer, N. and Jungclaus, J. H.: Evolution of the seasonal temperature cycle in a transient Holocene simulation: orbital forcing and sea-ice, Clim. Past, 7, 1139-1148, doi:10.5194/cp-7-1139-2011, 2011.

Fischer, N. and Jungclaus, J. H.: Holocene experiment with coupled atmosphere-ocean-model ECHAM5/MPI-OM, doi:10.1594/PANGAEA.773607, 2012.

Fleitmann, D., Burns, S. J., Mudelsee, M., Neff, U., Kramers, J., Mangini, A., and Matter, A.: Holocene forcing of the indian monsoon recorded in a stalagmite from southern Oman, Science, 300, 1737-1739, 2003.

Fraedrich, K., Jansen, H., Kirk, E., Luksch, U., and Lunkeit, F.: The Planet Simulator: Towards a user friendly model, Meteorol. Zeitschrift, 14, 299-304, 2005.

Francus, P., von Suchodoletz, H., Dietze, M., von Donner, R., Bouchard, F., Roy, A.-J., Fagot, M., Verschuren, D., and Kröpelin, S.: Varved sediments of Lake Yoa (Ounianga Kebir, Chad) reveal progressive drying of the Sahara during the last 6100 years, Sedimentology, doi:10.1111/j.13653091.2012.01370.x, 2013.

Haberkorn, K.: Reconstruction of the Holocene climate using an atmosphere-ocean-biosphere model and proxy data, Hamburg University, Dissertation, 2013.

Herzschuh, U.: Palaeo-moisture evolution at the margins of the Asian monsoon during the last $50 \mathrm{ka}$, Quaternary Sci. Rev., 25, 163-178, 2003.

Hu, C., Henderson, G. M., Huang, J., Xie, S., Sun, Y., and Johnson, K. R.: Quantification of Holocene Asian monsoon rainfall from spatially separated cave records, Earth Planet. Sci. Lett., 266, 221-232, 2008.

Huang, R., Chen, J., Wang, L., and Lin, Z.: Characteristics, processes, and causes of the spatio-temporal variabilities of the east asian monsoon system, Adv. Atmos. Sci., 29, 910-942, 2012.

Indermuhle, A., Stocker, T., Joos, F., Fischer, H., Smith, H. J., Wahlen, M., Deck, B., Mastroianni, D., Tschumi, J., Blunier, T., Meyer, R., and Stauffer, B.: Holocene carbon-cycle dynamics 
based on $\mathrm{CO}_{2}$ trapped in ice at Taylor Dome, Antarctica, Nature, 398, 121-126, 1999.

Jin, L., Schneider, B., Park, W., Latif, M., Khon, V., and Zhang, X.: The spatial-temporal patterns of Asian summer monsoon precipitation in response to Holocene insolation change: a model-data synthesis, Quaternary Sci. Rev., 85, 47-62, 2014.

Jolly, D., Harrison, S. P., Damnati, B., and Bonnefille, R.: Simulated climate and biomes of africa during the late quaternary: Comparison with pollen and lake status data, Quaternary Sci. Rev., 17, 629-657, 1998.

Kang, I. S, Jin, K., Lau, K.-M., Shukla, J., Krishnamurthy, V., Schubert, S. D., Waliser, D. E., Stern, W. F., Satyan, V., Kitoh, A., Meehl, G. A., Kanamitsu, M., Ya, V., Akimasa Sumi, G., Wu, G., Liu, Y., and Kim, J.-K.: Intercomparison of atmospheric GCM simulated anomalies associated with the 1997/98 El Nino. J. Climate, 15, 2791-2805, 2002.

Khon, V. C., Park, W., Latif, M., Mokhov, I., and Schneider, B.: Response of the hydrological cycle to orbital and greenhouse gas forcing, Geophys. Res. Lett., 37, L19705, doi:10.1029/2010GL044377, 2010.

Kleidon, A.: The climate sensitivity to human appropriation of vegetation productivity and its thermodynamic characterization, Global Planet. Change, 54, 109-127, 2006.

Krishnamurti, T. N., Vijaya Kumar, T. S. V., and Mitra, A. K.: Seasonal climate prediction of Indian summer monsoon, in: The Asian Monsoon, edited by: Wang, B., Springer/Praxis Publishing, New York, 553-583, 2006.

Kropelin, S., Verschuren, D., Lezine, A. M., Eggermont, H., Cocquyt, C., Francus, P., Cazet, J. P., Fagot, M., Rumes, B., Russell, J. M., Darius, F., Conley, D. J., Schuster, M., von Suchodoletz, H., and Engstrom, D. R.: Climate-driven ecosystem succession in the sahara: The past 6000 years, Science, 320, 765-768, 2008.

Kutzbach, J. E.: Monsoon climate of the early holocene - climate experiment with the earths orbital parameters for 9000 years ago, Science, 214, 59-61, 1981.

Lau, K. M., Kim, K. M., and Yang, S.: Dynamical and boundary forcing characteristics of regional components of the asian summer monsoon, J. Clim., 13, 2461-2482, 2000.

Liu, J., Wang, B., Yim, S.-Y., Lee, J.-Y., Jhun, J.-G., and Ha, K.-J.: What drives the global summer monsoon over the past millennium?, Clim. Dynam., 39, 1063-1072, 2012.

Legutke, S. and Voss, R.: The Hamburg atmosphere-ocean couple circulation model ECHO-G, Technical Report 18, Deutsches Klimarechenzentrum, Hamburg, 1999.

Lorenz, S. J. and Lohmann, G.: Acceleration technique for Milankovitch type forcing in a coupled atmosphere-ocean circulation model: method and application for the Holocene, Climate Dyn., 23, 727-743, 2004.

Madec, G.: NEMO reference manual, ocean dynamics component: NEMO-OPA, Preliminary version, Note Pole Model. 27, Inst. Pierre-Simon Laplace, Paris, 2006.

Maher, B. A.: Holocene variability of the east asian summer monsoon from chinese cave records: A re-assessment, The Holocene, 18, 861-866, 2008.

Maher, B. A. and Hu, M.: A high-resolution record of holocene rainfall variations from the western chinese loess plateau: Antiphase behaviour of the african/indian and east asian summer monsoons, The Holocene, 16, 309-319, 2006.
Maher, B. A. and Thompson, R.: Oxygen isotopes from chinese caves: Records not of monsoon rainfall but of circulation regime, J. Quaternary Sci., 27, 615-624, 2012.

Marsland, S. J., Haak, H., Jungclaus, J. H., Latif, M., and Roske, F.: The Max-Planck-Institute global ocean/sea ice model with orthogonal curvilinear coordinates, Ocean Modell., 5, 91-127, 2003.

Marzin, C. and Braconnot, P.: Variations of indian and african monsoons induced by insolation changes at 6 and $9.5 \mathrm{kyr}$ bp, Clim. Dynam., 33, 215-231, 2009.

Maier-Reimer, E., Mikolajewicz, U., and Hasselmann, K.: Mean circulation of the Hamburg LSG OGCM and its sensitivity to the thermohaline surface forcing. J. Phys. Oceanogr., 23, 731-757, 1993.

Park, W., Keenlyside, N., Latif, M., Stroeh, A., Redler, R., Roeckner, E., and Madec, G.: Tropical Pacific climate and its response to global warming in the Kiel Climate Model, J. Clim., 22, 7192, 2009.

Peyron, O., Jolly, D., Braconnot, P., Bonnefille, R., Guiot, J., Wirrmann, D., and Chalie, F.: Quantitative reconstructions of annual rainfall in africa 6000 years ago: Modeldata comparison, J. Geophys. Res.-Atmos., 111, D24110, doi:10.1029/2006jd007396, 2006.

Pfeiffer, M. and Lohmann, G.: The Last Interglacial as Simulated by an Atmosphere-Ocean General Circulation Model: Sensitivity Studies on the Influence of the Greenland Ice Sheet, in: Earth System Science: Bridging the Gaps between Disciplines Perspectives from a Multi-disciplinary Helmholtz Research School, SpringerBriefs in Earth System Sciences, edited by: Lohmann, G., Grosfeld, K., Wolf-Gladrow, D., Unnithan, V., Notholt, J., and Wegner, A., ISBN 978-3-642-32234-1; Springer, Heidelberg, 57-64, 2013.

Prasad, S. and Enzel, Y.: Holocene paleoclimates of india, Quaternary Res., 66, 442-453, 2006.

Raddatz, T. J., Reick, C. H., Knorr, W., Kattge, J., Roeckner, E., Schnur, R., Schnitzler, K. G., Wetzel, P., and Jungclaus, J.: Will the tropical land biosphere dominate the climate-carbon cycle feedback during the twenty-first century?, Clim. Dynam., 29, 565-574, 2007.

Randall, D. A., Wood, R. A., Bony, S., Colman, R., Fichefet, T., Fyfe, J., Kattsov, V., Pitman, A., Shukla, J., Srinivasan, J., Stouffer, R. J., Sumi, A., and Taylor, K. E.: Cilmate Models and Their Evaluation ,in: Climate Change 2007: The Physical Science Basis. Contribution of Working Group I to the Fourth Assessment Report of the Intergovernmental Panel on Climate Change, edited by: [Solomon, S., Qin, D., Manning, M., Chen, Z., Marquis, M., Averyt, K. B.,Tignor, M. and Miller, H., Cambridge University Press, Cambridge, United Kingdom and New York, NY, USA, 2007.

Roeckner, E., Arpe, K., Bengtsson, L., Christoph, M., Claussen, M., Duemenil, L., Esch, M., Giorgetta, M., Schlese, U., and Schulzweida, U.: The atmospheric general circulation model ECHAM-4: model description and simulation of the present day climate, Max-Planck-Institut fur Meteorologie Rep. 218, 1996.

Roeckner, E., Baeuml, G., Bonaventura, L., Brokopf, R., Esch, M., Giorgetta, M., Hagemann, S., Kirchner, I., Kornblueh, L., Manzini, E., Rhodin, A., Schlese, U., Schulzweida, U., and Tompkins, A.: The atmospheric general circulation model 
ECHAM5, Part I: Model description, Max Planck Institute for Meteorology Rep. 349, 2003.

Ruddiman, W. F.: What is the timing of orbital-scale monsoon changes?, Quaternary Sci. Rev., 25, 657-658, 2006.

Ruddiman, W. F.: Earth's Climate: Past and Future, 2nd revised edition, W.H. Freeman and Company, p. 388, 2008.

Trenberth, K. E., Stepaniak, D. P., and Caron, J. M.: The global monsoon as seen through the divergent atmospheric circulation, J. Climate, 13, 3969-3993, 2000.

Uppala, S. M., Kallberg, P. W., Simmons, A. J., Andrae, U., Bechtold, V. D., Fiorino, M., Gibson, J. K., Haseler, J., Hernandez, A., Kelly, G. A., Li, X., Onogi, K., Saarinen, S., Sokka, N., Allan, R. P., Andersson, E., Arpe, K., Balmaseda, M. A., Beljaars, A. C. M., Van De Berg, L., Bidlot, J., Bormann, N., Caires, S., Chevallier, F., Dethof, A., Dragosavac, M., Fisher, M., Fuentes, M., Hagemann, S., Holm, E., Hoskins, B. J., Isaksen, L., Janssen, P., Jenne, R., McNally, A. P., Mahfouf, J. F., Morcrette, J. J., Rayner, N. A., Saunders, R. W., Simon, P., Sterl, A., Trenberth, K. E., Untch, A., Vasiljevic, D., Viterbo, P., and Woollen, J.: The era40 re-analysis, Quart. J. Roy. Meteorol. Soc., 131, 2961-3012, 2005.

Varma, V., Prange, M., Merkel, U., Kleinen, T., Lohmann, G., Pfeiffer, M., Renssen, H., Wagner, A., Wagner, S., and Schulz, M.: Holocene evolution of the Southern Hemisphere westerly winds in transient simulations with global climate models, Clim. Past, 8, 391-402, doi:10.5194/cp-8-391-2012, 2012

Wang, B. and LinHo: Rainy season of the asian-pacific summer monsoon, J. Climate, 15, 386-398, 2002.

Wang, B., Wu, R. G., and Lau, K. M.: Interannual variability of the Asian summer monsoon: Contrasts between theI and the western north pacific-east Asian monsoons, J. Climate, 14, 4073-4090, 2001.

Wang, B., Clemens, S. C., and Liu, P.: Contrasting the Indian and East Asian monsoons: Implications on geologic timescales, Mar. Geol., 201, 5-21, 2003.

Wang, B., Liu, J., Kim, H. J., Webster, P. J., Yim, S. Y., and Xiang, B.: Northern Hemisphere summer monsoon intensified by megael nino/southern oscillation and atlantic multidecadal oscillation, Proc. Natl. Acad. Sci. USA, 110, 5347-5352, 2013.

Wang, B. E.: The Asian monsoon, Springer praxis books, Springer/Praxis Publishing Co, Berlin, 787 pp., 2006.

Wang, P.: Global monsoon in a geological perspective, Chinese Sci. Bull., 54, 1113-1136, 2009.

Wagner, S.: ECHO-G transient simulation 7000BP-4500BP (orbit only): atmosphere 12 HOUR raw data. World Data Center for Climate, CERA-DB "EH4T30L19_HOPE-GL20_OE1_12H", available at: http://cera-www.dkrz.de/WDCC/ui/Compact.jsp? acronym=EH4T30L19_HOPE-GL20_OE1_12H, 2007.
Wagner, S., Widmann, M., Jones, J., Haberzettl, T., Lucke, A., Mayr, C., Ohlendorf, C., Schabitz, F., and Zolitschka, B.: Transient simulations, empirical reconstructions and forcing mechanisms for the mid-holocene hydrological climate in southern patagonia, Clim. Dynam., 29, 333-355, 2007.

Wang, T., Wang, H. J, and Jiang, D. B: Mid-Holocene East Asian summer climate as simulated by the PMIP2 models, Palaeogeogr. Palaeoclimatol. Palaeoecol., 288, 93-102, 2010.

Wang, Y., Cheng, H., Edwards, R. L., He, Y., Kong, X., An, Z., Wu, J., Kelly, M. J., Dykoski, C. A., and Li, X.: The Holocene Asian monsoon: Links to solar changes and north atlantic climate, Science, 308, 854-857, 2005.

Wang, Y., Liu, X., and Herzschuh, U.: Asynchronous evolution of the indian and east asian summer monsoon indicated by holocene moisture patterns in monsoonal central asia, Earth-Sci. Rev., 103, 135-153, 2010.

Webster, P. J., Magana, V. O., Palmer, T. N., Shukla, J., Tomas, R. A., Yanai, M., and Yasunari, T.: Monsoons: Processes, predictability, and the prospects for prediction, J. Geophys. Res.Oc., 103, 14451-14510, 1998.

Wolff, J., Maier-Reimer, E., and Legutke, S.: The Hamburg Primitive Equation Model HOPE. Technical report 18, German Climate Computer Center (DKRZ), 1997.

Xie, P. and P.A. Arkin: Global precipitation: A 17-year monthly analysis based on gauge observations, satellite estimates, and numerical model outputs, Bull. Amer. Meteor. Soc., 78, 2539-2558, 1997.

Yihui, D. and Zunya, W.: A study of rainy seasons in China, Meteorol. Atmos. Phys., 100, 121-138, 2008.

Zhao, Y. and Harrison, S. P.: Mid-holocene monsoons: A multimodel analysis of the inter-hemispheric differences in the responses to orbital forcing and ocean feedbacks, Clim. Dynam., 39, 1457-1487, 2011.

Zhou, T., Wu, B., Scaife, A. A., Brönnimann, S., Cherchi, A., Fereday, D., Fischer, A. M., Folland, C. K., Jin, K. E., Kinter, J., Knight, J. R., Kucharski, F., Kusunoki, S., Lau, N.-C., Li, L., Nath, M. J., Nakaegawa, T., Navarra, A., Pegion, P., Rozanov, E., Schubert, S., Sporyshev, P., Voldoire, A., Wen, X., Yoon, J. H., and Zeng, N.: The CLIVAR C20C Project: Which components of the Asian-Australian-Monsoon variability are forced and reproducible?, Clim. Dyn., 33, 1051-1068, 2009. 